\title{
Escritórios de planta livre: o impacto de diferentes soluções de fachada na eficiência energética
}

\author{
Open-plan offices: the impact of different facade \\ solutions on energy efficiency
}

\section{Rosilene Regolão Brugnera \\ Ricardo Mateus \\ J oão Adriano Rossignolo \\ Karin Maria Soares Chvatal}

\section{Resumo}

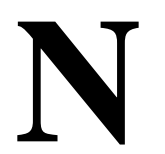

o Brasil, os edifícios de escritórios de planta livre têm se destacado pela utilização de fachadas totalmente envidraçadas, aspecto que pode impactar diretamente o consumo de energia do ar condicionado. $\mathrm{O}$ objetivo deste estudo é classificar e caracterizar o desempenho energético de edifícios de escritório de planta livre em três climas brasileiros. Simulações computacionais foram realizadas no programa EnergyPlus, a fim de verificar o impacto de vários parâmetros (clima, tipo de fachada, PAF, tipo de vidro, dispositivo de sombreamento e temperatura de setpoint) no consumo de energia do ar condicionado. Os resultados, classificados em faixas de desempenho energético, mostraram que alterar de uma fachada tradicional (alvenaria) para uma fachada cortina (totalmente envidraçada) elevou o consumo de energia do ar condicionado em média 25\% para Curitiba e São Paulo e 15\% para Manaus; que o PAF foi o parâmetro que mais impactou esse consumo, e o tipo de vidro teve mais impacto nas maiores aberturas; que utilizar um dispositivo de sombreamento sempre gerou economia e a elevação em $1{ }^{\circ} \mathrm{C}$ do setpoint de resfriamento reduziu o consumo, em média, até $16,4 \%$. Tais resultados geraram as melhores combinações desses parâmetros para cada clima, podendo servir de suporte aos projetistas, no sentido de se criar edifícios energeticamente mais eficientes.

Palavras-chave: Eficiência energética. Soluções de fachada. Escritórios de planta livre. Simulação computacional.

\section{Abstract}

In Brazil, open-plan office buildings are increasingly using fully glazed

${ }^{1}$ Rosilene Regolão Brugnera

${ }^{1}$ Universidade de São Paulo São Carlos - SP - Brasil

${ }^{2}$ Ricardo Mateus ${ }^{2}$ Universidade do Minho Guimarães - Portugal

3] oão Adriano Rossignolo 3Universidade de São Paulo Pirassununga - SP - Brasil

${ }^{4}$ Karin Maria Soares Chvatal ${ }^{4}$ Universidade de São Paulo São Carlos - SP - Brasil

Recebido em 08/11/18 Aceito em 30/01/19 facades, an aspect that can directly impact air-conditioning consumption. This study aims at classifying and characterising the energy performance of openplan office buildings in three Brazilian climates. Computational simulations were performed in the EnergyPlus program to verify the impact of various parameters (climate, type of facade, WWR, type of glass, shading device and setpoint temperature) on air-conditioning consumption. The results, classified in energy performance levels, showed that changing from traditional facades (masonry) to curtain facades (fully glazed), increased energy consumption with air-conditioning by an average of 25\% in Curitiba and São Paulo and $15 \%$ in Manaus; the WWR was the parameter that most impacted this consumption, and the glass type had most impact in the larger openings; using a shading device always generated savings and $a 1^{\circ} \mathrm{C}$ increase in the cooling setpoint reduced consumption by an average of $16.4 \%$. The results allowed to identify the best combinations of these parameters for each climate which can help designers to create more energy efficient buildings.

Keywords: Energy efficiency. Facade solutions. Open-plan offices. Computer simulation. 


\section{Introdução}

O setor da construção civil consome mais de um terço do total de energia primária no mundo e emite similares quantidades de $\mathrm{CO}_{2}$ (BORGSTEIN; LAMBERTS; HENSEN, 2016; YOSHINO; HONG; NORD, 2017). O investimento em políticas que promovam a eficiência energética pode ser considerado a chave para o desenvolvimento sustentável e a mitigação das alterações climáticas (PÉREZ-LOMBARD; ORTIZ; VELÁZQUEZ, 2013). Assim, as decisões iniciais de projeto estão diretamente relacionadas ao consumo energético da edificação, e 22\% desse consumo está atrelado à qualidade do envelope e $6 \%$ à geometria (VENÂNCIO; PEDRINI, 2009). A fachada, considerada o maior componente construtivo, exerce significativa influência no consumo de energia das edificações (AZARI, 2014). Desse modo, é fundamental se pensar em soluções de projeto e estratégias aplicadas a esse elemento a fim de melhorar o desempenho ambiental e energético da edificação (MARCONDES; ALUCCI; GONÇALVES, 2012).

No Brasil, cerca de 48,5\% do consumo de energia elétrica advém do setor de edificações (CONSELHO..., 2014). De acordo com o Balanço Energético Nacional de 2018 (ano-base 2017), os edifícios comerciais representam $14,4 \%$ do consumo total de energia elétrica (EMPRESA..., 2018). Esse tipo de edificação reflete o crescimento econômico do país e essa tipologia está concentrada em cidades como São Paulo e Rio de Janeiro. Nessas cidades houve uma crescente demanda por edifícios de "alto padrão", denominados "triple A", ou classe “AAA”, classificados a partir do padrão construtivo e sistemas prediais da edificação (VERONEZI; LIMA JUNIOR; ALENCAR, 2005). Esses edifícios seguem padrões arquitetônicos vinculados ao Estilo Internacional ${ }^{1}$, com fachadas totalmente envidraçadas, escritórios de planta livre, leiautes flexíveis e sistemas de iluminação artificial e ar condicionado para manter as condições ambientais internas constantes (DALZIEL, 2003). Consequentemente, cerca de $50 \%$ do consumo energético nesses edifícios advém do sistema de ar condicionado (CONSELHO..., 2014).

Huang e Niu (2015), em um panorama sobre a otimização do envelope construtivo baseado em simulações, apontam que cerca de $80 \%$ dos estudos estão relacionados à redução do consumo energético da edificação. E os principais parâmetros de análise são:
(a) transmitância térmica (valor de U);
(b) absortância;
(c) percentual de abertura na fachada (PAF);
(d) tipo de vidro;
(e) espessura do material de isolamento;
(f) formato do envelope construtivo; e
(g) presença e/ou dimensão de dispositivos de proteção solar.

A literatura (internacional e nacional) apresenta diversos estudos, a partir de simulação computacional, que demonstram como tais parâmetros da fachada influenciam o consumo de energia dos edifícios comerciais. No Quadro 1 destacam-se os estudos mais relevantes, dos quais se apresentam a geometria, os aspectos avaliados, os parâmetros variados e as principais recomendações. Um ponto importante a se destacar é o fato de se ter estudos de vários climas do mundo e do Brasil, com geometrias variadas, pois não se encontrou uma gama de estudos específicos para edifícios de planta livre, sobretudo no Brasil. 
Quadro 1 - Panorama dos trabalhos sobre avaliação de desempenho energético apresentados na literatura (Continua...)

\begin{tabular}{|c|c|c|}
\hline Referência/geometria & Parâmetros analisados & $\begin{array}{l}\text { Principais conclusões/ } \\
\text { recomendações }\end{array}$ \\
\hline Carvalho, La Rovere e Gonçalves (2010) & $\begin{array}{l}\text { - Consumo energético } \\
\text { (total/ar condicionado) } \\
\text { - Variações: vidros: simples } \\
\text { e duplo; inserção de brises; } \\
\text { alteração material da fachada } \\
\text { (substituição da pele de vidro } \\
\text { por alvenaria); Clima: Rio de } \\
\text { Janeiro (Brasil) }\end{array}$ & $\begin{array}{l}\text { - Protetores solares (em todas as } \\
\text { fachadas): redução de } 6 \% \text { do AC } \\
\text { ( } 4 \% \text { do total de energia); } \\
\text { - Uso do vidro incolor: aumento de } \\
\text { até } 19 \% \text { do AC (12\% do total de } \\
\text { energia); } \\
\text { - Melhores soluções: vidros eficientes } \\
\text { (duplo), paredes externas com cores } \\
\text { claras, materiais com baixa } \\
\text { transmitância térmica. }\end{array}$ \\
\hline Tsi & $\begin{array}{l}\text { - Consumo energético (ar } \\
\text { condicionado) } \\
\text { - Variações: PAF; valor U } \\
\text { das janelas; orientação } \\
\text { solar; dispositivos de } \\
\text { sombreamento móveis; } \\
\text { climas: Atenas (Grécia), } \\
\text { Lárnaca (Chipre), Lisboa } \\
\text { (Portugal), Málaga } \\
\text { (Espanha) e Roma (Itália) }\end{array}$ & $\begin{array}{l}\text { - Desempenho das janelas em climas } \\
\text { quentes depende de suas } \\
\text { propriedades termofísicas; } \\
\text { - Janela com vidro claro, melhor } \\
\text { utilizar valor de U moderado (entre } \\
2,00 \text { e 3,20W/ (m². K)); } \\
\text { - Presença de sombreamento - } \\
\text { redução da carga para resfriamento } \\
\text { de } 7 \% \text { em média. }\end{array}$ \\
\hline $\mathrm{Be}$ & $\begin{array}{l}\text { - Desempenho energético } \\
\text { - Conforto térmico } \\
\text { - Variações: PAF; tipo de } \\
\text { vidro; climas: São Paulo, } \\
\text { Rio de Janeiro, Fortaleza e } \\
\text { Curitiba (Brasil) }\end{array}$ & $\begin{array}{l}\text { - Desempenho energético: quanto } \\
\text { maior o PAF e o fator solar do } \\
\text { vidro, maior o consumo de energia } \\
\text { final; } \\
\text { - Vidro incolor - grande consumo de } \\
\text { energia; } \\
\text { - Em climas amenos não há grande } \\
\text { diferença entre o vidro laminado e o } \\
\text { duplo; } \\
\text { - Em climas quentes, o vidro duplo } \\
\text { promove economia de energia } \\
\text { maior. }\end{array}$ \\
\hline Boyar & $\begin{array}{l}\text { - Desempenho energético } \\
\text { (redução da demanda de } \\
\text { energia final para } \\
\text { aquecimento, resfriamento } \\
\text { e iluminação) } \\
\text { - Variações: PAF; tipo de } \\
\text { vidro; controle de } \\
\text { iluminação artificial } \\
\text { (dimerizável); valor de U } \\
\text { (paredes externas e } \\
\text { janelas); orientação solar; } \\
\text { climas: Tallinn (frio), } \\
\text { Londres (intermediário) e } \\
\text { Madri (quente). }\end{array}$ & $\begin{array}{l}\text { - Nas melhores combinações de } \\
\text { parâmetros (controle da iluminação, } \\
\text { vidros triplos, aumento do } \\
\text { isolamento das paredes externas e } \\
\text { orientação solar), foram obtidas } \\
\text { economias na ordem de até } 36 \% \\
\text { (com o controle total de } \\
\text { iluminação), 16\% (substituição do } \\
\text { vidro duplo pelo triplo), 8\% (pelo } \\
\text { aumento do isolamento das paredes } \\
\text { externas) e até 14\% (pela mudança } \\
\text { na orientação de leste/oeste para } \\
\text { norte/sul). }\end{array}$ \\
\hline Ihara, Gustavsen e Jelle (2015) & \multirow{4}{*}{$\begin{array}{l}\text { - Desempenho energético } \\
\text { (redução da demanda de } \\
\text { energia para aquecimento e } \\
\text { resfriamento) } \\
\text { - Variações: formato da } \\
\text { edificação; no de andares; } \\
\text { PAF; índice SHGC das } \\
\text { janelas; refletância solar; } \\
\text { valor de U (paredes } \\
\text { externas e da janela); } \\
\text { clima: Tóquio (Japão). }\end{array}$} & \multirow{4}{*}{$\begin{array}{l}\text { - Formas de reduzir a demanda de } \\
\text { energia: } 1^{\circ} \text { ) redução do valor de } \\
\text { SHGC; } 2^{\circ} \text { ) redução do valor de U da } \\
\text { janela; } 3^{\circ} \text { ) aumento da refletância } \\
\text { solar; } \\
\text { - Observou-se que a redução do valor } \\
\text { U das partes opacas da fachada } \\
\text { aumentou a demanda de energia nos } \\
\text { edifícios altos, enquanto nos } \\
\text { edifícios baixos ocorreu o contrário } \\
\text { - destaque para a utilização } \\
\text { adequada do valor U para o modelo } \\
\text { de edificação. }\end{array}$} \\
\hline $\begin{array}{c}\text { Office } \\
\text { arca }\end{array}$ & & \\
\hline Office area & & \\
\hline $\begin{array}{c}\text { Office } \\
\text { area }\end{array}$ & & \\
\hline
\end{tabular}


Quadro 1 - Panorama dos trabalhos sobre avaliação de desempenho energético apresentados na literatura (continuação)

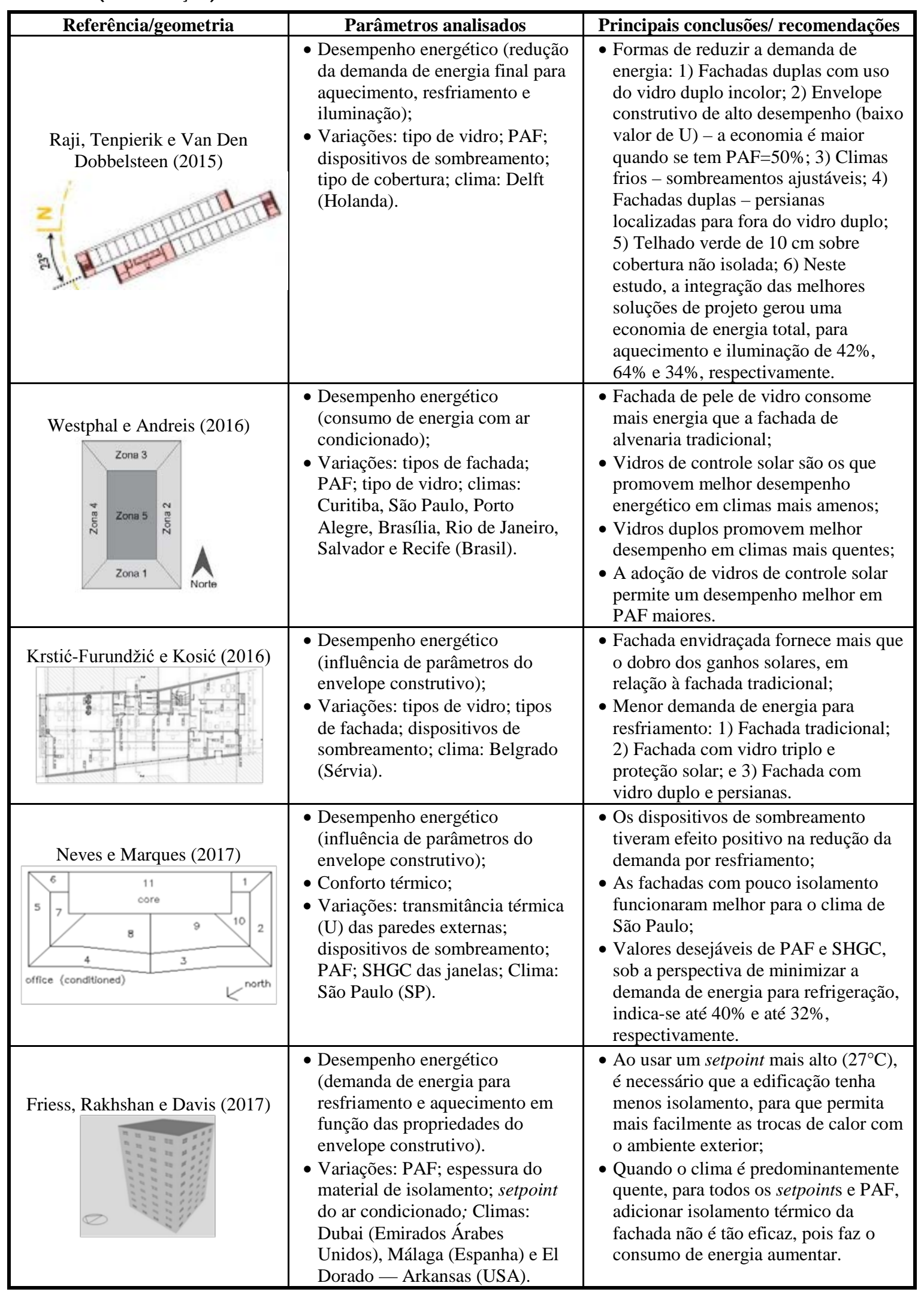


Tais estudos apresentam, de maneira geral, a importância de se conhecer a influência dos parâmetros da fachada no consumo energético dos edifícios comerciais. A partir disso, buscou-se nos estudos brasileiros os aspectos específicos mais relevantes a serem considerados para essa pesquisa, dos quais se destacam:

(a) a densidade de carga interna (pessoas, equipamentos e iluminação) geralmente são dados fixos da simulação (CARVALHO; LA ROVERE; GONÇALVES, 2010; PASQUALI et al., 2011; VENÂNCIO; PEDRINI, 2009; WESTPHAL; ANDREIS, 2016), embora quanto maior a densidade, maior será o consumo de energia (sobretudo se estiver associada a um elevado isolamento térmico) (RUZICKI et al., 2016);

(b) os dados da envolvente opaca (valor de U e absortância) possuem maior impacto nas fachadas com percentual de abertura na fachada (PAF) menores (MELO; LAMBERTS, 2008; NEVES; MARQUES, 2017), e fachadas com maior isolamento quase sempre geram sobreaquecimento (MELO et al., 2015; NEVES; MARQUES, 2017; WESTPHAL; ANDREIS, 2016);

(c) a orientação solar e o formato da edificação, especialmente em termos de exposição das áreas envidraçadas, têm grande influência no consumo de energia das edificações. O formato está diretamente relacionado aos parâmetros do envelope construtivo, que podem aumentar os ganhos de calor por radiação solar (MELO; LAMBERTS, 2008; VENÂNCIO; PEDRINI, 2009);

(d) o PAF é um dos parâmetros que mais impacta os ganhos de calor nas edificações e, portanto, influencia no seu consumo de energia (MELO; LAMBERTS, 2008; NEVES; MARQUES, 2017; VENÂNCIO; PEDRINI, 2009; WESTPHAL; ANDREIS, 2016);

(e) a utilização de um dispositivo de proteção solar causou redução de 5,8\% no consumo de energia total para um edifício institucional na cidade de Natal (VENÂNCIO; PEDRINI, 2009); redução de $6,35 \%$ no consumo de energia com ar condicionado para uma edificação comercial localizada no Rio de Janeiro (CARVALHO; LA ROVERE; GONÇALVES, 2010) e redução de $9 \%$ a 12,5\% para uma edificação comercial localizada em São Paulo (NEVES; MARQUES, 2017); e

(f) a alteração dos parâmetros construtivos da fachada (PAF, tipo de vidro) em edifícios localizados em climas quentes, como o de São Luís (MELO; LAMBERTS, 2008), Rio de Janeiro e Salvador (CARVALHO; LA ROVERE; GONÇALVES, 2010; WESTPHAL; ANDREIS,
2016), não causaria um grande aumento do consumo de energia com ar condicionado, pois ele já é elevado.

Conforme supracitado, os estudos apresentados (sobretudo brasileiros) não apresentam uma análise de desempenho energético específica para edifícios de escritórios de planta livre. Usar um envelope construtivo inadequado pode causar aumento no consumo de energia, principalmente devido aos ganhos de calor advindos da radiação solar (MIRRAHIMI et al., 2016).

Identificada essa lacuna, o objetivo deste trabalho é classificar e caracterizar o desempenho energético de edifícios de escritórios de planta livre em diferentes climas brasileiros, considerando o impacto da alteração dos parâmetros relacionados à fachada nesse consumo, tais como:

(a) tipo de fachada (definido pela sua composição construtiva);

(b) percentual de abertura na fachada (PAF);

(c) tipo de vidro;

(d) presença ou não de dispositivo de sombreamento; e

(e) setpoint do ar condicionado.

Os resultados deste estudo poderão dar suporte a decisões de projeto, no sentido de se desenvolver edifícios energeticamente mais eficientes.

\section{Método}

Para se obter o desempenho energético de edifícios de planta livre, efetuaram-se simulações computacionais paramétricas no programa EnergyPlus, versão 8.1 (DEPARTMENT..., 2013).

O método dessa pesquisa está dividido em cinco etapas, sendo:

(a) seleção dos climas;

(b) coleta de dados;

(c) definição do edifício de estudo e de suas características construtivas;

(d) definição das características de uso e do sistema de ar condicionado; e

(e) definição da metodologia utilizada na análise dos resultados.

\section{Seleção dos climas}

De acordo com a norma NBR 15220-3 (ABNT, 2005b), o Brasil é dividido em oito zonas bioclimáticas e, dentre essas zonas, foram selecionados três climas, a saber: 
(a) Zona bioclimática mais fria (Curitiba/PR zona 1) - Região Sul;

(b) Zona bioclimática intermediária (São Paulo/SP - zona 3) — Região Sudeste; e

(c) Zona bioclimática mais quente (Manaus/AM zona 8) — Região Norte.

O Quadro 2 apresenta (a) a localização das cidades no Brasil, a temperatura do ar e a umidade relativa anual para (b) Curitiba, (c) São Paulo e (d) Manaus.

Na classificação de Köppen-Geiger (KÖPPEN, 1936), o clima de Curitiba é considerado Cfb (clima temperado, com verão ameno), enquanto São Paulo é Cwa (clima subtropical/tropical de altitude, com verão quente e inverno seco) e Manaus é Af (clima tropical chuvoso de floresta) (ALVARES et al., 2013; AYOADE, 1996; ROLIM et al., 2007). E tais características podem ser observadas na Tabela 2. O clima de Manaus possui uma amplitude térmica menor e altas temperaturas, com temperaturas médias das mínimas e máximas variando de $20,9^{\circ} \mathrm{C}$ a $36,7^{\circ} \mathrm{C}$ ao longo do ano, se comparado a Curitiba, cujas mesmas temperaturas variam de $3,8^{\circ} \mathrm{C}$ a 31,7 ${ }^{\circ} \mathrm{C}$, e São Paulo, que variam de $8,6{ }^{\circ} \mathrm{C}$ a $33,4{ }^{\circ} \mathrm{C}$. Para as simulações foram utilizados arquivos climáticos (INMET, no formato epw) desenvolvidos por Roriz (2012) e Labeee (LABORATÓRIO..., 2015).

Quadro 2 - Descrição dos dados climáticos: (a) localização; (b) (c) e (d) temperatura e umidade relativa para Curitiba, São Paulo e Manaus, respectivamente

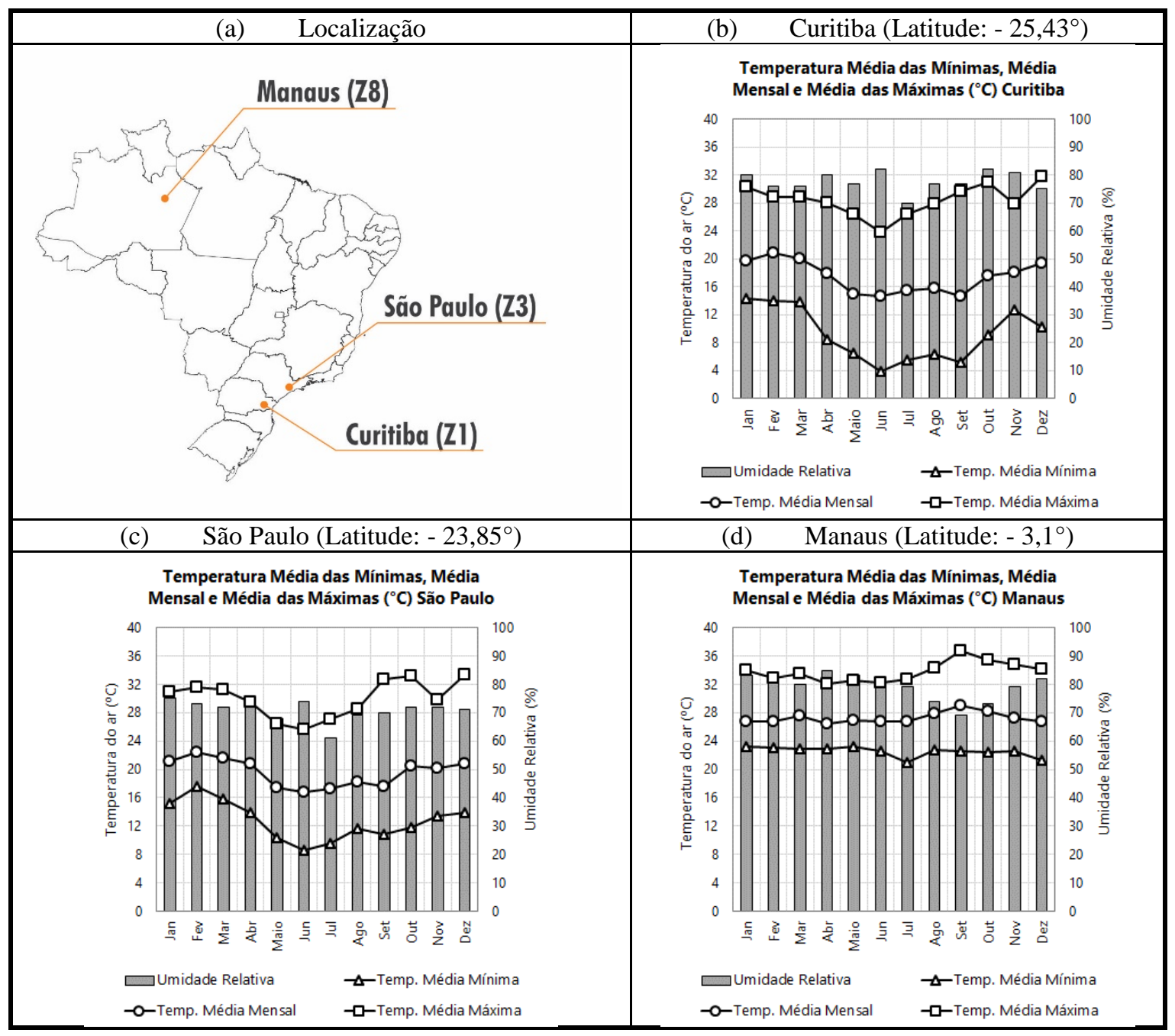




\section{Coleta de dados}

A etapa de coleta de dados teve como foco principal a busca por edificações comerciais do tipo escritório de planta livre, característica recorrente na atualidade dessa tipologia arquitetônica no mercado da construção civil brasileiro. A coleta foi realizada em três fontes: literatura (a partir de estudos brasileiros que avaliaram o desempenho energético de edifícios de escritórios), entrevistas com especialistas (consultoria de eficiência energética de edifícios de escritórios de alto padrão em São Paulo) e busca na base de dados da empresa Buildings (BUILDINGS, 2016) (focada em regiões de maior concentração desse tipo de edifício em São Paulo, tais como as avenidas Berrini, Paulista e na região do bairro de Pinheiros, de onde se obteve uma amostra de 142 edificações). Os resultados dessa coleta de dados são apresentados na Tabela 3.

A partir da Tabela 1 foram identificadas algumas características recorrentes, tais como:
(a) área condicionada em torno de $1.000 \mathrm{~m}^{2}$;
(b) pé-direito livre em torno de 2,70 m;
(c) PAF entre $50 \%$ e $80 \%$;
(d) fachada pele de vidro;
(e) ar condicionado do tipo variable refrigerant flow (VRF), f) piso elevado; e
(f) forro de gesso.

Tais características embasaram a criação de um modelo hipotético mais próximo da realidade.

\section{Tabela 1 - Características obtidas na etapa de coleta de dados}

\begin{tabular}{|c|c|c|c|}
\hline \multirow{2}{*}{$\begin{array}{l}\text { Características da } \\
\text { edificação }\end{array}$} & \multicolumn{3}{|c|}{ Referências (valores médios) } \\
\hline & Literatura & Entrevistas & $\begin{array}{l}\text { Banco de dados } \\
\text { buildings }\end{array}$ \\
\hline $\begin{array}{l}\text { Formato do } \\
\text { pavimento tipo }\end{array}$ & $\begin{array}{l}\text { Quadrado (30 m x } 30 \text { m; } 35 \\
\text { m x } 35 \text { m); } \\
\text { Retangular (26 m x } 15 \text { m; } 40 \\
\text { m x } 60 \text { m). } \\
\text { Ambos com núcleo (core) }{ }^{1}\end{array}$ & Variável & Variável \\
\hline $\begin{array}{l}\text { Área do pavimento } \\
\text { tipo }\left(\mathrm{m}^{2}\right)\end{array}$ & $\begin{array}{l}950 \mathrm{~m}^{2} \\
\text { (variou de } 900 \mathrm{~m}^{2} \text { a } 2.500 \\
\mathrm{~m}^{2} \text { ) }\end{array}$ & $\begin{array}{l}\text { Área condicionada entre } \\
3.000 \mathrm{~m}^{2} \text { e } 50.000 \mathrm{~m}^{2} \\
\text { (edifício como um todo) }\end{array}$ & $924 \mathrm{~m}^{2}$ \\
\hline Pé-direito (m) & $2,90 \mathrm{~m}$ & $\begin{array}{l}2,50 \mathrm{~m} \text { a } 3 \mathrm{~m} \text { (útil); } 3,70 \\
\mathrm{~m} \text { a } 4,20 \mathrm{~m} \text { (total - } \\
\text { galerias técnicas entre } \\
0,80 \mathrm{~m} \text { e } 1,00 \mathrm{~m})\end{array}$ & $2,80 \mathrm{~m}$ \\
\hline $\mathbf{N}^{\circ}$ de andares & 10 & Dado não informado & 17 \\
\hline PAF (\%) ${ }^{2}$ & $30-100$ & $50-80$ & Dado não informado \\
\hline Tipo de fachada & $\begin{array}{l}\text { Combinação alvenaria (ou } \\
\text { drywall) + vidro; } \\
\text { pele de vidro }\end{array}$ & Pele de vidro & Variável \\
\hline Tipo de vidro & Incolor, refletivo, duplo & $\begin{array}{l}\text { Vidro com baixo fator } \\
\text { solar }\end{array}$ & Dado não informado \\
\hline Cargas internas & $\begin{array}{l}\text { Iluminação: } 12 \mathrm{~W} / \mathrm{m}^{2} \\
\text { Pessoas: } 8 \mathrm{~m}^{2} / \text { pessoa; } 117 \mathrm{~W} \\
\text { Equipamentos: } 16,2 \mathrm{~W} / \mathrm{m}^{2}\end{array}$ & Dado não informado & Dado não informado \\
\hline Ar condicionado & $\begin{array}{l}\text { Tipo: split; central; } \\
\text { Temperatura de controle: } 25 \\
{ }^{\circ} \mathrm{C} \text { (resfr.); } 18{ }^{\circ} \mathrm{C} \text { (aquec.) }\end{array}$ & $\begin{array}{l}\text { Tipo: VRF (sistema } \\
\text { unitário); temperatura de } \\
\text { controle de } 20^{\circ} \mathrm{C} \text { a } 24^{\circ} \mathrm{C}\end{array}$ & Tipo: central \\
\hline Tipo de piso & Piso elevado com carpete & Dado não informado & $\begin{array}{l}\text { Piso elevado com } \\
\text { estrutura metálica }\end{array}$ \\
\hline Tipo de forro & Forro de gesso & Dado não informado & Forro modular \\
\hline $\begin{array}{l}N^{\circ} \text { de zonas } \\
\text { térmicas }\end{array}$ & 5 ( $4+$ core $)$ & Não se aplica & Não se aplica \\
\hline
\end{tabular}

Nota: ${ }^{1}$ Core - zona localizada no centro da edificação, um núcleo, geralmente utilizado em edifício de escritórios, onde se localizam as caixas de escada, elevadores, banheiros e copa; e ${ }^{2}$ PAF - Percentual de abertura na fachada. 


\section{Definição do edifício de estudo e de suas características construtivas}

A partir das características apresentadas no Quadro 2, um edifício virtual foi criado. O pavimento tipo desse edifício é apresentado na Figura 1. Ele possui geometria retangular, área total de $800 \mathrm{~m}^{2}$ (20 m x $40 \mathrm{~m})$, núcleo (core) de $300 \mathrm{~m}^{2}(10 \mathrm{~m}$ x $30 \mathrm{~m})$ e pédireito de 2,70 m (3,75 m no total - somando-se a área do forro e do piso elevado). O núcleo é uma área destinada a serviços, elevadores, copa, banheiros e escada e não é climatizado. A distância entre a fachada e o core é de $5 \mathrm{~m}$ - região de influência da radiação sobre o ambiente interno para definição de uma zona térmica (AMERICAN..., 2013). Apenas a área pertencente aos escritórios é condicionada termicamente e todo o perímetro da fachada é revestida - ao menos parcialmente -, por envidraçados. Além disso, o edifício possui as maiores fachadas orientadas a norte e sul. Tal escolha se deu em função de se optar pela situação que gerasse menores ganhos solares para o volume como um todo.

Para a avaliação do consumo energético da edificação, foi simulado apenas um pavimento, situado em um andar intermediário. Esse andar simulado (com piso e teto adiabáticos) funciona como um módulo do edifício, que representa o comportamento térmico dos demais pavimentos intermediários. Esse modelo (Figura 1) foi dividido em cinco zonas térmicas (quatro para os escritórios e uma para o core), conforme procedimento indicado pela norma ASHRAE 90.1 (AMERICAN..., 2013). A divisão entre as áreas dos escritórios foi realizada por paredes virtuais (superfícies fictícias de espaços de ar), configuradas utilizando-se apenas a resistência do ar.
O PAF representa o percentual de área envidraçada na fachada. Ele considera a área útil da fachada, disponível para a colocação de janelas (sendo o pédireito interno do ambiente de 2,70 m). Assim, considerando o mesmo PAF para fachadas diferentes, foram definidos para este estudo três valores (30\%, 55\% e 80\%) que representam janelas pequenas $(30 \%)$, menos comuns, médias e grandes (55\% e 80\%).

Foram selecionados dois tipos de fachada, denominados fachada tradicional (FT) e fachada cortina (FC). A fachada tradicional (FT) tem a parte opaca composta por parede de alvenaria e a área envidraçada por esquadrias entre vãos. A outra opção, fachada cortina (FC), é revestida inteiramente por vidro. No atual mercado da construção de edifícios de escritórios, as fachadas cortina têm substituído as tradicionais, de acordo com o levantamento de campo presente no Quadro 2.

Para a área transparente da fachada, foram selecionados quatro tipos de vidro, com características diferentes, sendo eles:
(a) incolor;
(b) low-e;
(c) refletivo claro; e
(d) duplo com baixo fator solar.

Na fachada cortina, a parte opaca da estrutura interna (peitoril em alvenaria e viga de concreto) é revestida por um vidro com película PVB (polivinil butiral) branca, que o deixa com aspecto translúcido. As principais propriedades térmicas desses vidros são apresentadas na Tabela 2.

\section{Figura 1 - Pavimento tipo do edifício}

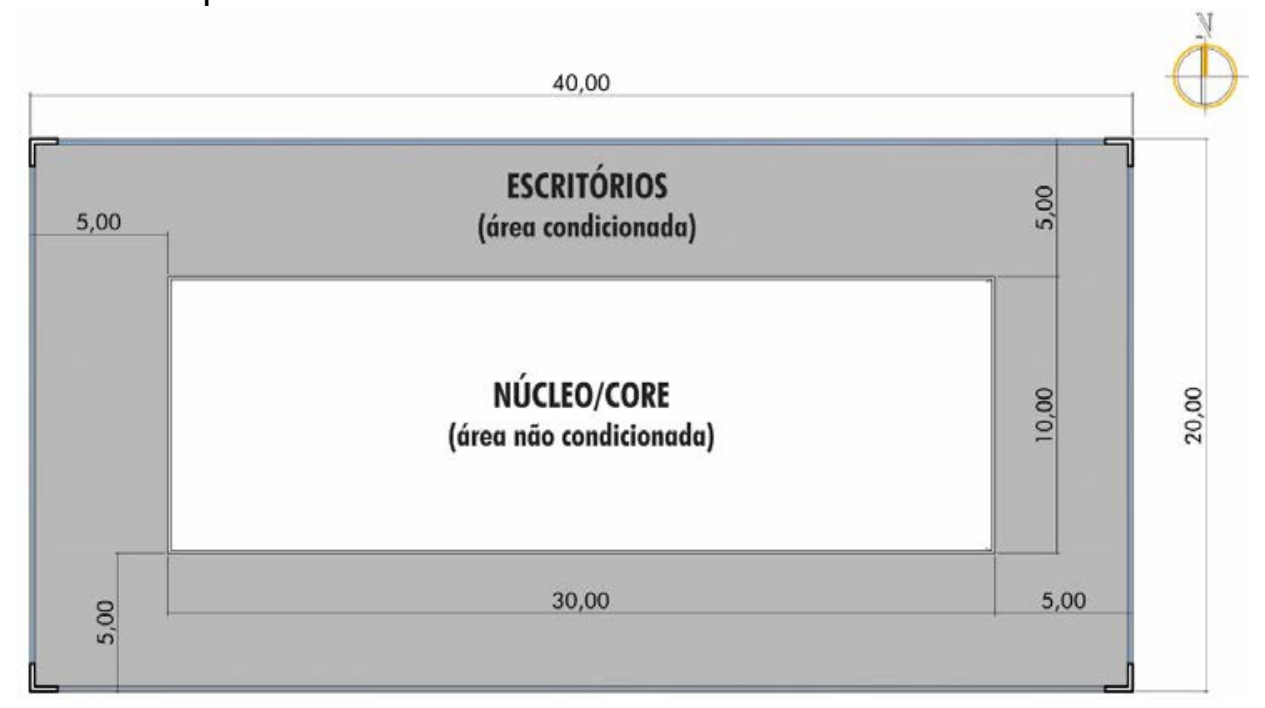


Tabela 2 - Propriedades termofísicas dos vidros utilizados no modelo

\begin{tabular}{l|c|c|c|c|c}
\hline & $\begin{array}{c}\text { Incolor } \\
(\mathbf{I n})\end{array}$ & $\begin{array}{c}\text { Low-e } \\
(\mathbf{L w})\end{array}$ & $\begin{array}{c}\text { Refletivo } \\
\text { (Rf) }\end{array}$ & $\begin{array}{c}\text { Duplo } \\
\text { (Dp) }\end{array}$ & Translúcido \\
\hline Espessura (mm) & 6 & 6 & 8 & 24 & 8 \\
\hline $\begin{array}{l}\text { Transmitância à radiação solar no } \\
\text { espectro visível (incidência normal) (\%) }\end{array}$ & 0,88 & 0,32 & 0,72 & 0,39 & 0,65 \\
\hline Transmitância térmica (W/m²) & 5,70 & 5,79 & 5,67 & 2,79 & 5,50 \\
\hline Fator solar (\%) & 82 & 54 & 44 & 28 & 62 \\
\hline
\end{tabular}

Fonte: Cebrace (2016), CB3E \& Abividro (2015), Guardian (2010) e Glassec-Viracon (2016).

Foi utilizado um dispositivo de sombreamento horizontal (1,26 $\mathrm{m}$ de largura) que abrangeu igualmente toda a extensão das fachadas. Esse dispositivo foi modelado no EnergyPlus e sua dimensão foi selecionada por corresponder à máscara de sombra do maior PAF (80\%), garantindo que, para os demais PAFs, também haja o sombreamento efetivo (total) no período indicado. A intenção aqui era avaliar apenas o impacto de se ter ou não os ganhos de calor reduzidos devido a uma proteção solar. Assim, foi calculado um dispositivo de sombreamento único cuja máscara de sombra atingisse esse objetivo: a redução dos ganhos solares, em todos as combinações de PAF, orientação e latitude.

O piso é elevado com carpete, o forro é de gesso, com um espaço de ar entre a laje e o forro (espaço para instalações), as paredes internas pertencentes ao núcleo central são de drywall e as paredes externas são de alvenaria de bloco de concreto (para a fachada tradicional e para a fachada cortina essa parte se constitui como o peitoril). A Tabela 3 apresenta os detalhes construtivos referentes às fachadas e aos materiais.

\section{Definição das características de uso e do sistema de ar condicionado}

A densidade de carga térmica abrange os ganhos de calor advindos das pessoas, equipamentos e iluminação artificial. O modelo de edificação possui uma área climatizada, referente aos escritórios e uma área não climatizada, pertencente às áreas de serviços, escadas, elevadores, etc. Tais cargas são consideradas apenas para a área dos escritórios, sendo dados fixos da simulação, pois sofrem influência direta do uso da edificação. O padrão horário de ocupação é de segunda à sexta-feira, das $8 \mathrm{~h}$ às 19h, conforme apresentado no Quadro 3.

O sistema de ar condicionado selecionado para o estudo é do tipo variable refrigerant flow (VRF). Esse sistema é do tipo central de expansão direta com múltiplas unidades evaporadoras. A capacidade foi calculada pelo EnergyPlus, de acordo com a especificação de cada clima, para a obtenção do coeficiente de performance (COP) do sistema, de acordo com as normas RTQ-C (INMETRO, 2013) e ASHRAE 90.1 (AMERICAN..., 2013). A partir do cálculo da capacidade do aparelho, foi selecionado um COP para obtenção da maior classificação energética (nível A) (Quadro 4). O sistema de ar condicionado foi simulado para aquecimento e resfriamento, com temperaturas de setpoint de $18{ }^{\circ} \mathrm{C}$ e $24{ }^{\circ} \mathrm{C}$, respectivamente, de acordo com os dados utilizados na literatura (BESEN; WESTPHAL, 2012, 2014; CARLO, 2008; DIDONÉ; WAGNER; PEREIRA, 2014; MELO et al., 2015; MELO; LAMBERTS, 2008; SANTANA, 2006; WESTPHAL, 2007; WESTPHAL; LAMBERTS, 2007). Para resfriamento foi testado um setpoint de $25^{\circ} \mathrm{C}$, para verificar sua influência no consumo de energia da edificação.

\section{Forma de análise dos resultados}

Os resultados das simulações são apresentados da seguinte forma:

(a) considerações sobre os consumos de energia total (Ec) (equipamentos, iluminação e ar condicionado), separados por uso final; e

(b) classificação dos consumos de energia dos 288 cenários avaliados, em cinco níveis de desempenho energético, conforme apresentado na Tabela 4. A partir dos valores de consumo máximos e mínimos referentes a cada clima, os resultados foram divididos em cinco níveis iguais, classificados em uma escala de cores, em que os menores consumos se concentram na faixa verde escura e os maiores, na faixa do vermelho.

A partir de tal classificação, é realizada a apresentação da influência dos parâmetros avaliados neste estudo: clima, PAF, tipo de vidro, presença ou não do dispositivo de sombreamento e a temperatura de controle do ar condicionado) no consumo de energia do ar condicionado. 
Resultados e discussão

\section{Consumo de energia por uso final}

O consumo de energia total anual do escritório de planta livre é composto da soma dos consumos de iluminação (IL), equipamentos (EQ) e ar condicionado (AC), conforme apresentado na Figura 2, que se refere aos 288 cenários simulados. Os valores de EQ e LG foram sempre os mesmos, pois a densidade de carga de equipamentos e de iluminação foi considerada fixa, conforme descrito em Método. Já os valores de AC foram variáveis, representando de $17 \%$ a $52 \%$ do consumo total, dependendo da combinação de parâmetros referente ao cenário em questão (tipo de fachada, vidro, entre outros). Dessa forma, nos resultados das seções seguintes, é apresentado apenas o consumo de energia do ar condicionado.

O consumo de energia do ar condicionado se refere apenas ao seu uso no modo de refrigeração. Devido ao clima das localizações estudadas e à ocupação do edifício ser somente durante o dia, não houve consumo significativo para aquecimento em nenhum dos cenários avaliados.

\section{Tabela 3 - Tipos de fachadas e detalhamento de seu sistema construtivo}

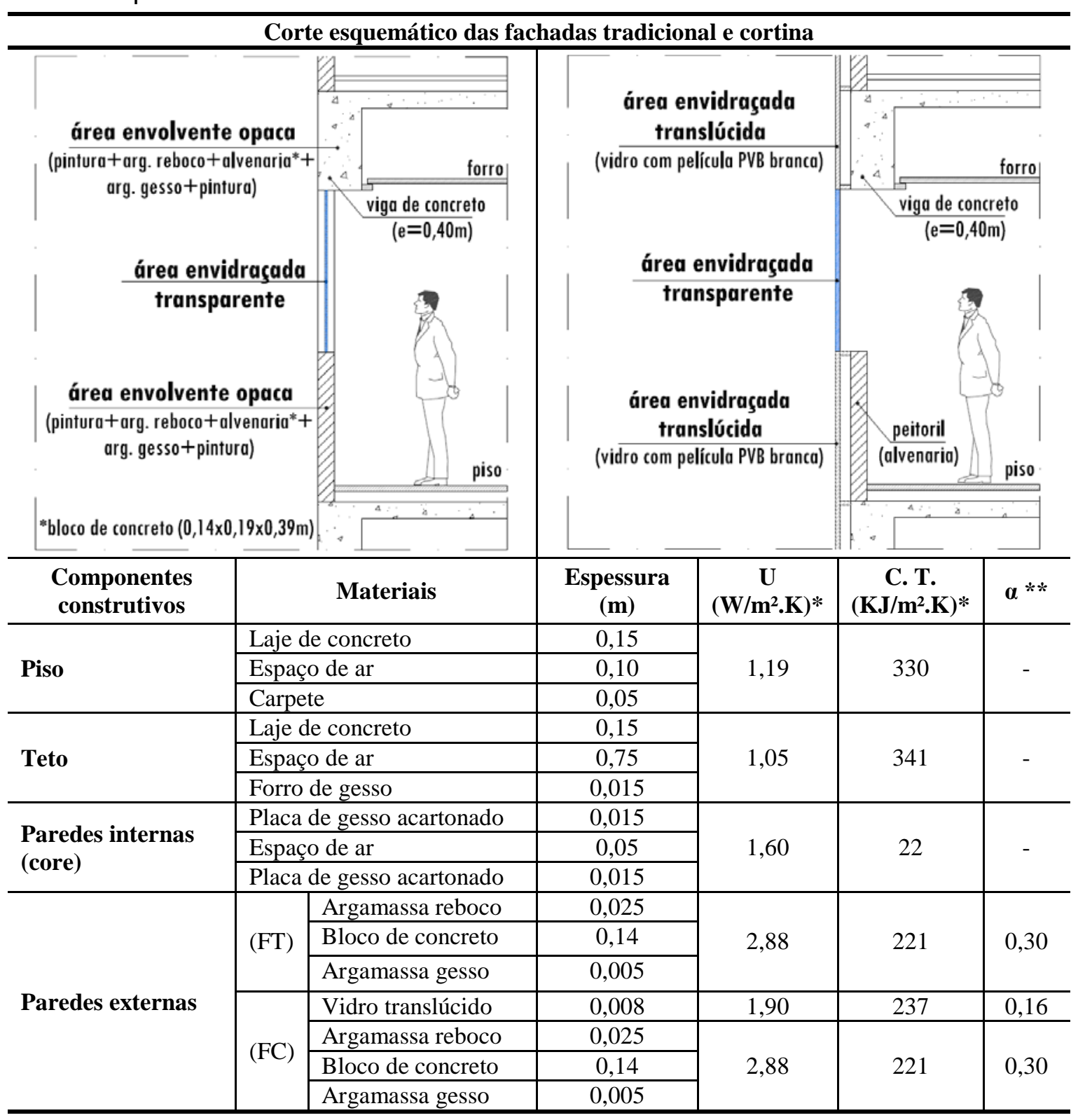

Nota: *a transmitância térmica (U) e a capacidade térmica (C.T.) foram calculadas com base na norma NBR 15220: desempenho térmico de edificações: parte 2: métodos de cálculo da transmitância térmica, da capacidade térmica, do atraso térmico e do fator solar de elementos e componentes de edificações (ABNT, 2005a); e **a = Absortância solar. 
Quadro 3 - Características das cargas internas

\begin{tabular}{|l|l|l|}
\hline \multicolumn{1}{|c|}{ Tipo } & \multicolumn{1}{|c|}{ Características } & \multicolumn{1}{c|}{ Referências } \\
\hline Pessoas & $8 \mathrm{~m}^{2} /$ pessoa; 117 W/pessoa & $\begin{array}{l}\text { NBR 16401 (ABNT, 2008); ASHRAE } \\
\text { Fundamentals (AMERICAN..., 2009) }\end{array}$ \\
\hline Equipamentos* & $16,2 \mathrm{~W} / \mathrm{m}^{2}$ (média/alta) & NBR 16401-1(ABNT, 2008) \\
\hline Iluminação artificial & Tipo: on-off**; 9,7 W/m² & RTQ-C (INSTITUTO..., 2013) \\
\hline
\end{tabular}

Nota: *a densidade de carga dos equipamentos refere-se à um computador e monitor, além de impressora e fax, para cada posto de trabalho (1 posto de trabalho/ pessoa); e **sistema de iluminação on-off, acionado durante o período ocupado sem considerar o aproveitamento da iluminação natural (não é dimerizável, eficiente).

\section{Quadro 4 - Características do sistema de ar condicionado}

\begin{tabular}{|l|l|}
\hline & \multicolumn{1}{|c|}{ Características } \\
\hline Tipo de equipamento & VRF com condensação a ar \\
\hline Capacidade & $\geq 40 \mathrm{~kW} \mathrm{e}<70 \mathrm{~kW}$ \\
\hline Classificação & Multi-split VRF \\
\hline COP (nível A): Curitiba e São Paulo & 3,11 \\
\hline COP (nível A): Manaus & 2,78 \\
\hline Temperatura de controle (resfriamento) & $24^{\circ} \mathrm{C} / 25^{\circ} \mathrm{C}$ \\
\hline Temperatura de controle (aquecimento) & $18^{\circ} \mathrm{C}$ \\
\hline
\end{tabular}

Fonte: RTQ-C (INSTITUTO..., 2013) e ASHRAE 90.1 (AMERICAN..., 2013).

Tabela 4 - Classificação dos resultados em faixas de consumo energético

\begin{tabular}{|c|c|}
\hline \multicolumn{2}{|r|}{ Faixas de consumo energético } \\
\hline$>$ & Valor máximo de consumo energético assumido para cada clima \\
\hline & Ec $\geq \operatorname{Min}+4 *(\operatorname{Max}-\operatorname{Min}) / 5$ \\
\hline & Min+3*(Max-Min) $/ 5 \leq$ Ec $<$ Mín $+4 *($ Max-Min $) / 5$ \\
\hline & Min $+2 *($ Max-Min $) / 5 \leq$ Ec $<$ Min $+3 *($ Max-Min $) / 5$ \\
\hline & $\operatorname{Min}+1 *($ Max-Min $) / 5 \leq$ Ec $<$ Mín $+2 *($ Max-Min $) / 5$ \\
\hline & Ec $<$ Min $+1 *(\operatorname{Max}-\operatorname{Min}) / 5$ \\
\hline$<$ & Valor mínimo de consumo energético assumido para cada clima \\
\hline
\end{tabular}

Nota: Legenda:

Ec $=$ Energia consumida;

Mín = Valor mínimo de consumo energético obtido;

Máx = Valor máximo de consumo energético obtido; e

Valores de consumo em $\mathrm{kWh} / \mathrm{m}^{2}$. ano.

Figura 2 - Composição do consumo de energia total

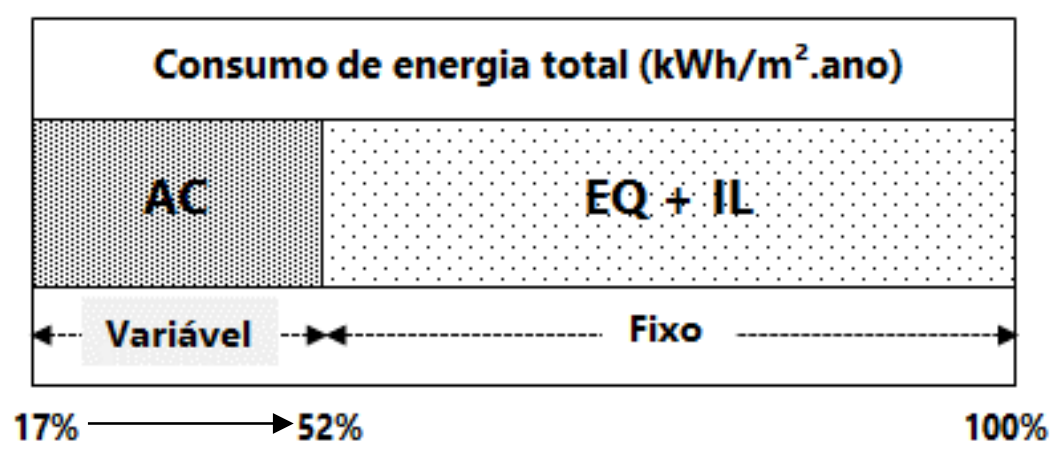




\section{Classificação em faixas de consumo energético}

A Tabela 5 apresenta o consumo de energia anual do ar condicionado para todas as combinações de parâmetros simuladas. Para cada clima, esses consumos foram agrupados nas faixas de consumo energético definidas em Método, e a faixa verde escura corresponde aos menores valores e a faixa vermelha, aos maiores valores. As seções seguintes utilizam-se dessa tabela para apresentarem a influência dos parâmetros estudados (tipo de fachada, clima, parâmetros relacionados à janela e temperatura de setpoint) no consumo de energia do ar condicionado e como se comportam quanto à classificação em cores.

Tabela 5 - Classificação dos resultados em faixas de consumo energético

\begin{tabular}{|c|c|c|c|c|c|c|c|c|c|c|c|}
\hline & & \multirow{4}{*}{$\begin{array}{c}\text { Tipo de vidro } \\
\text { (dispositivo de } \\
\text { sombreamento) }\end{array}$} & \multicolumn{9}{|c|}{ Consumo de energia do ar condicionado $\left(\mathrm{kWh} / \mathrm{m}^{2}\right.$.ano) } \\
\hline & & & \multirow{2}{*}{\multicolumn{3}{|c|}{$\begin{array}{c}\text { Curitiba } \\
\text { PAF }\end{array}$}} & \multirow{2}{*}{\multicolumn{3}{|c|}{$\begin{array}{c}\text { São Paulo } \\
\text { PAF }\end{array}$}} & \multicolumn{3}{|c|}{ Manaus } \\
\hline & & & & & & & & & & PAF & \\
\hline & & & $30 \%$ & $55 \%$ & $\mathbf{8 0 \%}$ & $30 \%$ & $55 \%$ & $80 \%$ & $30 \%$ & $55 \%$ & $80 \%$ \\
\hline & \multirow{8}{*}{ 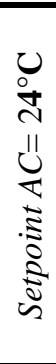 } & In (SDS) & 16,5 & 22,5 & 32,5 & 19,7 & 26,7 & 38,3 & 56,9 & 63,0 & 76,1 \\
\hline & & In (CDS) & 14,3 & 15,6 & 22,6 & 16,2 & 18,6 & 27,7 & 54,0 & 60,3 & 71,8 \\
\hline & & Lw (SDS) & 15,1 & 19,1 & 27,0 & 18,5 & 22,8 & 32,2 & 52,6 & 60,8 & 71,8 \\
\hline & & Lw (CDS) & 13,4 & 14,6 & 19,9 & 16,2 & 17,2 & 24,0 & 50,0 & 55,8 & 69,8 \\
\hline & & Rf (SDS) & 14,4 & 17,7 & 24,5 & 18,0 & 21,1 & 29,3 & 50,2 & 59,7 & 70,2 \\
\hline & & Rf (CDS) & 12,9 & 14,0 & 18,7 & 16,4 & 16,9 & 22,2 & 47,6 & 53,4 & 68,8 \\
\hline & & Dp (SDS) & 15,8 & 19,9 & 28,2 & 18,5 & 23,0 & 33,1 & 47,7 & 58,1 & 68,8 \\
\hline & & Dp (CDS) & 14,3 & 15,7 & 20,1 & 16,3 & 17,1 & 24,1 & 44,8 & 51,2 & 65,8 \\
\hline & \multirow{8}{*}{ 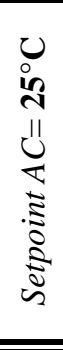 } & In (SD) & 13,8 & 19,2 & 28,3 & 17,3 & 22,9 & 33,4 & 51,0 & 58,6 & 71,1 \\
\hline & & In (CDS) & 11,6 & 13,0 & 19,4 & 14,9 & 15,7 & 23,4 & 47,7 & 55,4 & 66,8 \\
\hline & & Lw (SDS) & 12,3 & 16,2 & 23,2 & 16,1 & 19,7 & 27,7 & 46,3 & 56,2 & 66,9 \\
\hline & & Lw (CDS) & 10,6 & 11,8 & 16,9 & 14,8 & 15,3 & 19,9 & 43,5 & 51,3 & 64,6 \\
\hline & & $\mathrm{Rf}$ (SDS) & 11,6 & 15,0 & 20,9 & 15,9 & 18,5 & 25,0 & 43,8 & 54,8 & 65,2 \\
\hline & & Rf (CDS) & 10,1 & 11,2 & 15,7 & 14,9 & 15,2 & 18,4 & 41,3 & 48,4 & 63,3 \\
\hline & & Dp (SDS) & 13,2 & 17,4 & 25,1 & 16,5 & 19,9 & 29,1 & 41,9 & 53,0 & 64,7 \\
\hline & & Dp (CDS) & 11,4 & 13,3 & 18,2 & 15,2 & 15,4 & 20,7 & 39,2 & 45,3 & 61,3 \\
\hline \multirow{16}{*}{ 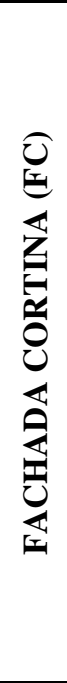 } & \multirow{8}{*}{ 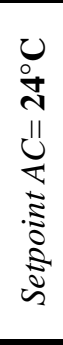 } & In (SDS) & 22,4 & 26,9 & 36,5 & 27,2 & 32,3 & 42,6 & 67,3 & 70,7 & 81,8 \\
\hline & & In (CDS) & 17,8 & 18,8 & 25,3 & 21,6 & 23,2 & 31,4 & 61,5 & 66,5 & 76,7 \\
\hline & & Lw (SDS) & 20,8 & 23,6 & 30,4 & 25,3 & 28,6 & 36,4 & 63,3 & 68,5 & 77,6 \\
\hline & & Lw (CDS) & 17,2 & 17,8 & 22,2 & 20,5 & 21,6 & 27,7 & 57,4 & 61,9 & 74,7 \\
\hline & & Rf (SDS) & 20,1 & 22,2 & 27,9 & 24,5 & 26,8 & 33,5 & 61,1 & 67,3 & 75,9 \\
\hline & & Rf (CDS) & 17,0 & 17,5 & 21,1 & 20,1 & 20,9 & 26,0 & 55,3 & 59,4 & 73,6 \\
\hline & & Dp (SDS) & 21,5 & 24,6 & 33,0 & 25,9 & 29,5 & 38,3 & 60,0 & 66,6 & 75,8 \\
\hline & & Dp (CDS) & 17,5 & 18,0 & 23,4 & 20,6 & 22,0 & 28,6 & 54,1 & 57,7 & 71,6 \\
\hline & \multirow{8}{*}{ 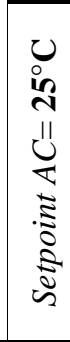 } & In (SDS) & 19,5 & 23,7 & 31,8 & 23,5 & 28,4 & 37,6 & 62,2 & 66,4 & 76,9 \\
\hline & & In (CDS) & 15,6 & 16,3 & 21,8 & 18,2 & 19,5 & 27,0 & 56,7 & 61,4 & 71,8 \\
\hline & & Lw (SDS) & 18,1 & 20,6 & 26,6 & 21,8 & 24,8 & 31,8 & 58,6 & 63,9 & 72,7 \\
\hline & & Lw (CDS) & 15,1 & 15,5 & 19,3 & 17,3 & 18,0 & 23,5 & 53,2 & 57,3 & 69,6 \\
\hline & & Rf (SDS) & 17,4 & 19,2 & 24,3 & 21,0 & 23,1 & 29,1 & 56,7 & 62,4 & 71,0 \\
\hline & & Rf (CDS) & 14,8 & 15,1 & 18,2 & 17,0 & 17,5 & 21,9 & 51,1 & 55,1 & 68,2 \\
\hline & & Dp (SDS) & 19,1 & 21,9 & 29,2 & 22,7 & 26,1 & 34,2 & 55,5 & 62,4 & 71,7 \\
\hline & & Dp (CDS) & 16,0 & 16,6 & 19,9 & 17,8 & 18,9 & 24,8 & 49,3 & 53,9 & 67,1 \\
\hline
\end{tabular}

Nota: Legenda:

$\mathrm{PAF}=$ percentual de abertura na fachada;

$\mathrm{FT}=$ fachada tradicional;

$\mathrm{FC}=$ fachada cortina;

Vidros: In =incolor; $L w=$ low-e; $R f=$ refletivo; e $\mathrm{Dp}=$ duplo;

SDS = sem dispositivo de sombreamento; e

$\mathrm{CDS}=$ com dispositivo de sombreamento. 


\section{Influência do tipo de fachada}

Foram consideradas duas alternativas de fachada: fachada tradicional e fachada cortina. Na Tabela 6 nota-se a diferença entre esses dois tipos de fachada pelas cores das faixas de consumo energético. A fachada tradicional (FT) possui a maioria dos cenários nas faixas verde escura ou clara. Isso demonstra o seu menor consumo energético em relação à fachada cortina (FC), que possui cenários em todas as cores, conforme pode ser mais bem observado na Figura 3. Pode-se notar que sempre houve aumento do consumo de energia do ar condicionado quando se alterou de uma fachada tradicional para uma fachada cortina. Esse aumento foi, em média, $25 \%$ para as cidades de Curitiba e São Paulo e $15 \%$ para Manaus. Destaca-se ainda a diferença entre os cenários com distintos PAFs. Conforme maior a área opaca da fachada, ou seja, quanto menor o PAF, maior é o impacto devido a alterações no seu sistema construtivo. Com isso, nas menores aberturas (PAF de 30\%), alcança-se aumentos de 50\% em Curitiba, 40\% em São Paulo e $30 \%$ em Manaus.

Figura 3 - Aumento do consumo de energia do ar condicionado em função da alteração do tipo de fachada (de FT para FC) para (a) Curitiba, (b) São Paulo e (c) Manaus

\section{Curitiba}

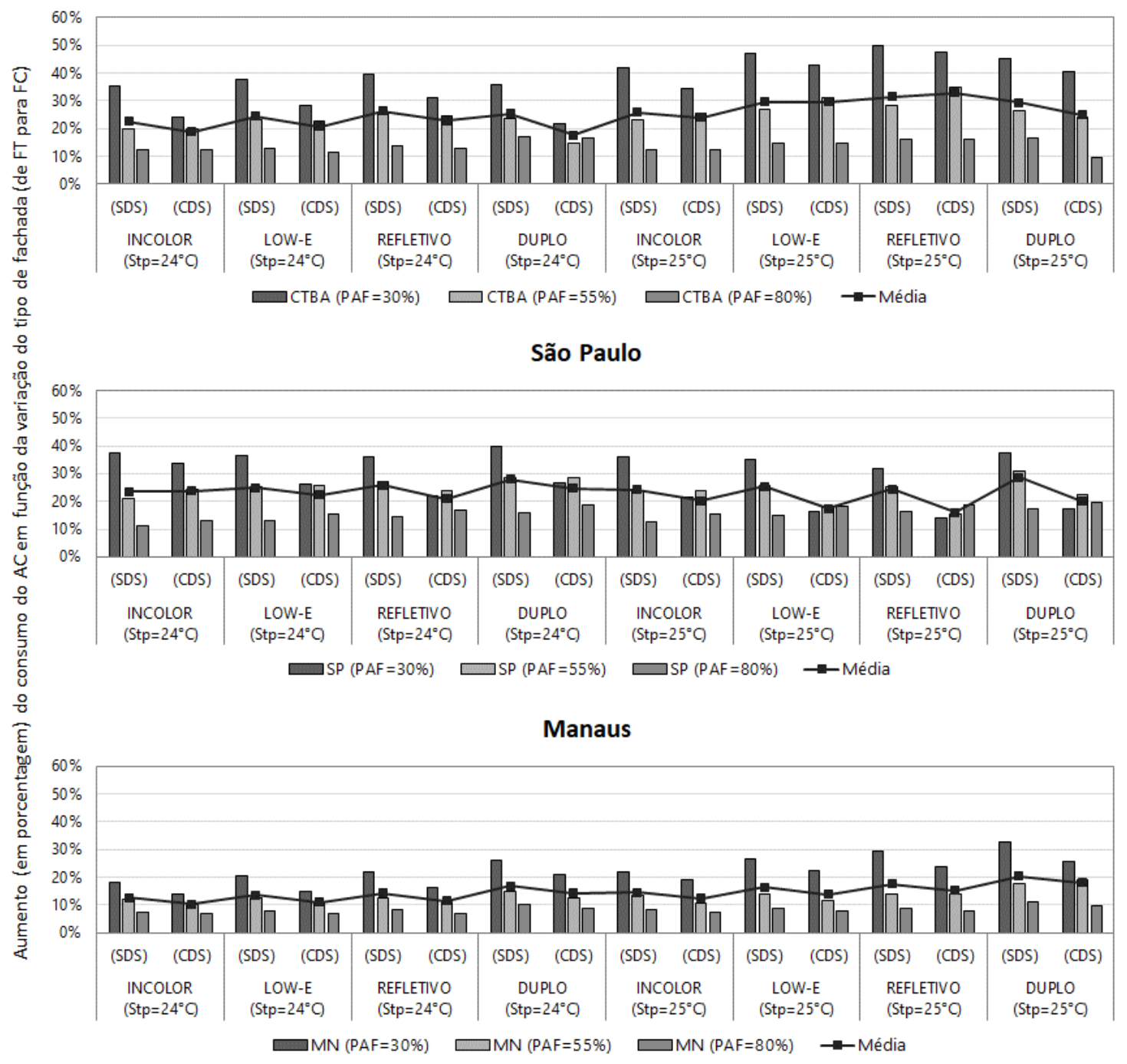




\section{Influência do clima}

A partir da Tabela 5, é possível se notar a diferença entre os climas, já que, quanto mais quente o local, maiores foram os consumos de energia. Como as faixas de consumo são calculadas considerando os menores e maiores valores obtidos para cada clima, isso permite notar que Curitiba e São Paulo (por mostrarem valores mais próximos entre si), apresentam mais possibilidades de se ter um desempenho melhor (maior quantidade de cenários nas cores verde escura/clara), diferenciando-se de Manaus, o clima mais quente (com mais cenários nas cores amarela, laranja e vermelha). Os valores máximos de consumo de energia do ar condicionado (em $\mathrm{kWh} / \mathrm{m}^{2}$. ano), para cada clima, apresentam-se da seguinte forma: Curitiba (FT: 32,5 / FC: 36,5), São Paulo (FT: 38,3 / FC: 42,6) e Manaus (FT: 76,1 / FC: 81,8). O clima de Manaus, quente e úmido, diferencia-se dos demais, por ter amplitudes muito inferiores e temperaturas mais altas ao longo de todo o ano (Quadro 1, em Método).

\section{Influência dos parâmetros relacionados às janelas}

Foram considerados nas simulações os seguintes parâmetros, relacionados às janelas localizadas nas quatro fachadas do edifício:

(a) percentual de abertura na fachada (PAF) (30\%, 55\% e 80\%);

(b) presença (CDS) ou não (SDS) de dispositivo de sombreamento; e

(c) tipo de vidro (incolor, low-e, refletivo e duplo).

Quanto ao PAF, nota-se na Tabela 5 que, com o seu aumento, houve sempre elevação no consumo de energia. Isso chegou a causar mudanças na classificação de desempenho energético (alteração das cores) da edificação em várias situações, principalmente para a fachada cortina e/ou o clima predominantemente quente e úmido (Manaus), que a alteração do PAF mudou as cores dos cenários, que passaram às classificações de cores amarela, laranja e vermelha, demonstrando assim os maiores consumos de energia.

Na fachada tradicional, ao se alterar o PAF de $30 \%$ para 55\%, o consumo de energia do ar condicionado aumentou em média 23\%; com o PAF de 55\% para $80 \%$ esse valor médio foi para $34 \%$, e para o PAF de $30 \%$ para $80 \%$ obteve-se aumento médio de $65 \%$ (Tabela 6). Na fachada cortina, essas variações médias foram de $12 \%$ (PAF de $30 \%$ para 55\%), $24 \%$ (PAF de $55 \%$ para $80 \%$ ) e $40 \%$ (PAF de $30 \%$ para $80 \%$ ). Observa-se que o aumento do consumo do ar condicionado não foi proporcional ao aumento do PAF, fato também observado nos estudos de Westphal e Andreis (2016). Os resultados da Tabela 10 referem-se aos cenários sem dispositivo de sombreamento e com setpoint de $24^{\circ} \mathrm{C}$. O impacto desse parâmetro nos demais cenários (com dispositivo de sombreamento e/ou setpoint de 25 ${ }^{\circ} \mathrm{C}$ ) apresentou padrões de resultados similares.

Com relação ao tipo de vidro, o vidro incolor foi o que apresentou o maior consumo de energia para todos os cenários. Na Tabela 5 nota-se que em alguns casos essas diferenças entre os vidros são suficientes para que haja alteração da faixa de desempenho - alterando as cores — , em outros, vidros distintos permanecem com a mesma classificação. Na Tabela 7 tem-se a redução desse consumo, com a adoção das alternativas estudadas. São apresentados os cenários da fachada cortina, com setpoint de $24{ }^{\circ} \mathrm{C}$ e sem dispositivo de sombreamento (SDS). O impacto desse parâmetro nos demais cenários (fachada tradicional, com dispositivo de sombreamento, setpoint de $25{ }^{\circ} \mathrm{C}$ ) apresentou-se de forma semelhante. Nos climas de Curitiba e São Paulo, a maior economia foi obtida com o vidro refletivo, seguido do low-e e do duplo, e as maiores reduções se deram na maior PAF (80\%). Nesse caso, a economia, com o uso do vidro refletivo, foi de 23,4\% (Curitiba) e 21,4\% (São Paulo). Já em Manaus o vidro de menor consumo foi o duplo, seguido do refletivo e do low-e, e o maior impacto foi observado na janela menor, com PAF de $30 \%$ (economia de $10,8 \%$ para o vidro duplo).

Finalmente, quanto ao dispositivo de sombreamento, a sua adoção sempre gerou economia de energia (Tabela 5), alterando a classificação por cores dos cenários, que passaram a ocupar classificações mais altas, em comparação com os cenários sem dispositivo de sombreamento. Tal resultado está em concordância com outros estudos em edifícios de planta livre no Brasil (CARVALHO; LA ROVERE; GONÇALVES, 2010; PASQUALI et al., 2011; NEVES; MARQUES, 2017). Conforme supracitado, foi calculado um dispositivo de sombreamento único cuja máscara de sombra atingisse esse objetivo: a redução dos ganhos solares, em todas as combinações de PAF, orientação e latitude, e isso pode ser verificado na Tabela 8 , a qual demonstra que ter o dispositivo de sombreamento sempre reduz o consumo energético nas situações aqui apresentadas. Como a eficiência do dispositivo de sombreamento é diferente em cada clima e PAF, tais resultados não podem ser comparados entre si, apenas refletem no consumo energético do ar condicionado o fato de se ter ou não o dispositivo de sombreamento. 


\section{Influência do setpoint de resfriamento}

A temperatura de controle (setpoint) de resfriamento do ar condicionado pode ser considerada um elemento possível de ser alterado em uma edificação em uso, e isso pode ser visto na Tabela 5, principalmente nos cenários com fachada cortina, para os climas avaliados, em que o aumento da temperatura de setpoint de resfriamento em $1^{\circ} \mathrm{C}$ reduziu o consumo energético de modo a alterar a faixa de desempenho, para classificações mais altas. E essa redução também pode ser vista na Tabela 9 , que apresenta o consumo de energia do ar condicionado para todos os cenários com fachada cortina (FC), com setpoint de $25^{\circ} \mathrm{C}$ em relação aos cenários com setpoint de $24^{\circ} \mathrm{C}$. O impacto desse parâmetro nos demais cenários (fachada tradicional) apresentou-se de forma semelhante.

Tabela 6 - Variação do consumo de energia do ar condicionado em função do PAF

\begin{tabular}{|c|c|c|c|c|c|}
\hline & \multirow{2}{*}{ Clima } & \multirow{2}{*}{$\begin{array}{l}\text { Tipo de vidro } \\
\text { (D. } \\
\text { sombreamento) }\end{array}$} & \multicolumn{3}{|c|}{ Consumo de energia do ar condicionado } \\
\hline & & & $30 \%-55 \%$ & $55 \%-80 \%$ & $30 \%-80 \%$ \\
\hline \multirow{12}{*}{ 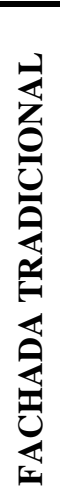 } & \multirow{4}{*}{ Curitiba } & In (SDS) & $+35,8 \%$ & $+44,6 \%$ & $+96,3 \%$ \\
\hline & & Lw (SDS) & $+26,4 \%$ & $+41,0 \%$ & $+78,1 \%$ \\
\hline & & Rf (SDS) & $+22,3 \%$ & $+38,9 \%$ & $+69,8 \%$ \\
\hline & & Dp (SDS) & $+26,0 \%$ & $+41,8 \%$ & $+78,6 \%$ \\
\hline & \multirow{4}{*}{ São paulo } & In (SDS) & $+35,1 \%$ & $+43,4 \%$ & $+93,8 \%$ \\
\hline & & Lw (SDS) & $+23,3 \%$ & $+40,8 \%$ & $+73,5 \%$ \\
\hline & & $\mathrm{Rf}(\mathrm{SDS})$ & $+16,9 \%$ & $+38,9 \%$ & $+62,4 \%$ \\
\hline & & Dp (SDS) & $+23,8 \%$ & $+44,1 \%$ & $+78,4 \%$ \\
\hline & \multirow{4}{*}{ Manaus } & In (SDS) & $+10,8 \%$ & $+20,7 \%$ & $+33,7 \%$ \\
\hline & & Lw (SDS) & $+15,6 \%$ & $+18,1 \%$ & $+36,5 \%$ \\
\hline & & Rf (SDS) & $+18,9 \%$ & $+17,6 \%$ & $+39,8 \%$ \\
\hline & & Dp (SDS) & $+21,8 \%$ & $+18,6 \%$ & $+44,4 \%$ \\
\hline \multirow{12}{*}{ 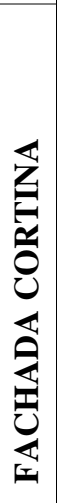 } & \multirow{4}{*}{ Curitiba } & In (SDS) & $+20,2 \%$ & $+35,6 \%$ & $+63,0 \%$ \\
\hline & & Lw (SDS) & $+13,3 \%$ & $+28,9 \%$ & $+46,0 \%$ \\
\hline & & $\mathrm{Rf}(\mathrm{SDS})$ & $+10,1 \%$ & $+26,1 \%$ & $+38,8 \%$ \\
\hline & & Dp (SDS) & $+14,5 \%$ & $+34,3 \%$ & $+53,8 \%$ \\
\hline & \multirow{4}{*}{ São paulo } & In (SDS) & $+19,0 \%$ & $+31,8 \%$ & $+56,8 \%$ \\
\hline & & Lw (SDS) & $+12,8 \%$ & $+27,5 \%$ & $+43,9 \%$ \\
\hline & & Rf (SDS) & $+9,6 \%$ & $+24,9 \%$ & $+36,8 \%$ \\
\hline & & Dp (SDS) & $+13,9 \%$ & $+29,5 \%$ & $+47,6 \%$ \\
\hline & \multirow{4}{*}{ Manaus } & In (SDS) & $+21,6 \%$ & $+15,7 \%$ & $+21,6 \%$ \\
\hline & & Lw (SDS) & $+22,5 \%$ & $+13,3 \%$ & $+22,5 \%$ \\
\hline & & Rf (SDS) & $+24,1 \%$ & $+12,8 \%$ & $+24,1 \%$ \\
\hline & & Dp (SDS) & $+26,2 \%$ & $+13,7 \%$ & $+26,2 \%$ \\
\hline
\end{tabular}

Nota: *em negrito encontram-se os maiores valores.

Tabela 7 - Variação do consumo de energia do ar condicionado em função do tipo de vidro (referência: vidro incolor $6 \mathrm{~mm}$ )

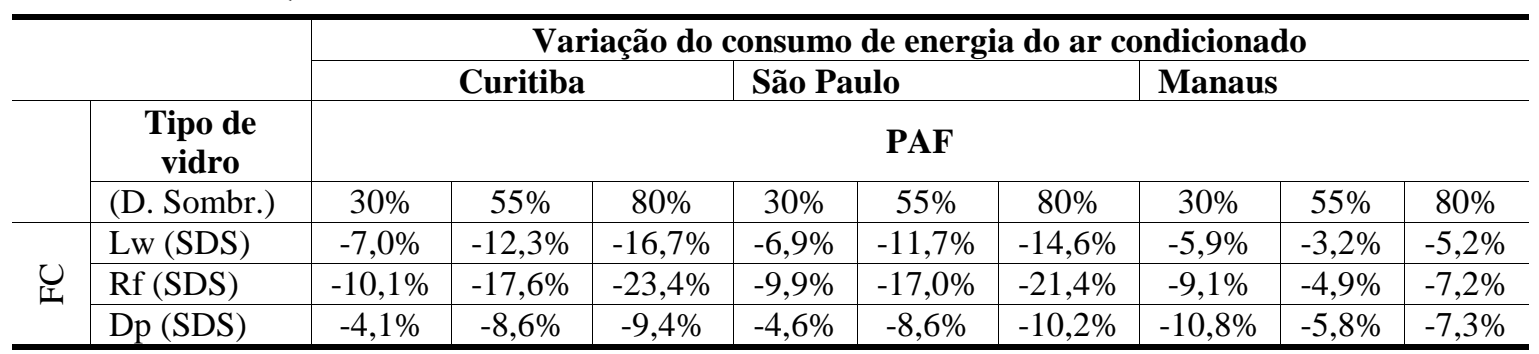

Nota: *em negrito encontram-se os maiores valores. 
Tabela 8 - Variação do consumo de energia do ar condicionado nos cenários com dispositivo de sombreamento (CDS) (referência: cenários sem dispositivo de sombreamento (SDS))

\begin{tabular}{|c|c|c|c|c|c|}
\hline & \multirow{2}{*}{ Clima } & \multirow{2}{*}{$\begin{array}{c}\text { Tipo de vidro } \\
\text { (Disp. sombreamento) }\end{array}$} & \multicolumn{3}{|c|}{ Variação do consumo de energia do ar condicionado } \\
\hline & & & PAF $=30 \%$ & PAF $=55 \%$ & PAF $=\mathbf{8 0} \%$ \\
\hline \multirow{12}{*}{ 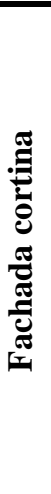 } & \multirow{4}{*}{ Curitiba } & In (CDS) & $-20,4 \%$ & $-30,3 \%$ & $-30,6 \%$ \\
\hline & & Lw (CDS) & $-17,4 \%$ & $-24,4 \%$ & $-27,0 \%$ \\
\hline & & Rf (CDS) & $-15,6 \%$ & $-21,2 \%$ & $-24,5 \%$ \\
\hline & & Dp (CDS) & $-18,6 \%$ & $-26,9 \%$ & $-29,1 \%$ \\
\hline & \multirow{4}{*}{$\begin{array}{l}\text { São } \\
\text { Paulo }\end{array}$} & In (CDS) & $-20,4 \%$ & $-28,3 \%$ & $-26,3 \%$ \\
\hline & & Lw (CDS) & $-19,1 \%$ & $-24,4 \%$ & $-24,0 \%$ \\
\hline & & Rf (CDS) & $-18,0 \%$ & $-22,0 \%$ & $-22,5 \%$ \\
\hline & & Dp (CDS) & $-20,5 \%$ & $-25,4 \%$ & $-25,3 \%$ \\
\hline & \multirow{4}{*}{ Manaus } & In (CDS) & $-8,7 \%$ & $-5,9 \%$ & $-6,2 \%$ \\
\hline & & Lw (CDS) & $-9,3 \%$ & $-9,6 \%$ & $-3,7 \%$ \\
\hline & & Rf (CDS) & $-9,5 \%$ & $-11,7 \%$ & $-3,0 \%$ \\
\hline & & Dp (CDS) & $-9,8 \%$ & $-13,5 \%$ & $-5,5 \%$ \\
\hline
\end{tabular}

Nota: *em negrito encontram-se os maiores valores.

Tabela 9 - Variação do consumo de energia do ar condicionado em função da alteração na temperatura de controle (setpoint) de $24^{\circ} \mathrm{C}$ para $25^{\circ} \mathrm{C}$

\begin{tabular}{|c|c|c|c|c|c|c|c|c|c|c|}
\hline & \multirow{4}{*}{$\begin{array}{c}\text { Tipo de } \\
\text { vidro } \\
\text { (D. Sombr.) }\end{array}$} & \multicolumn{9}{|c|}{ Variação do consumo de energia do ar condicionado } \\
\hline & & \multicolumn{3}{|c|}{ Curitiba } & \multicolumn{3}{|c|}{ São paulo } & \multicolumn{3}{|c|}{ Manaus } \\
\hline & & \multicolumn{9}{|c|}{ PAF } \\
\hline & & $30 \%$ & $55 \%$ & $80 \%$ & $30 \%$ & $55 \%$ & $80 \%$ & $30 \%$ & $55 \%$ & $80 \%$ \\
\hline \multirow{8}{*}{$\bigcup_{I}^{U}$} & In (SDS) & $-12,7 \%$ & $-12,0 \%$ & $-12,8 \%$ & $-13,6 \%$ & $-12,3 \%$ & $-11,7 \%$ & $-7,5 \%$ & $-6,0 \%$ & $-6,0 \%$ \\
\hline & In (CDS) & $-12,2 \%$ & $-12,9 \%$ & $-14,0 \%$ & $-16,1 \%$ & $-15,9 \%$ & $-14,1 \%$ & $-7,7 \%$ & $-7,7 \%$ & $-6,5 \%$ \\
\hline & Lw (SDS) & $-13,1 \%$ & $-12,8 \%$ & $-12,4 \%$ & $-13,9 \%$ & $-13,2 \%$ & $-12,6 \%$ & $-7,5 \%$ & $-6,6 \%$ & $-6,2 \%$ \\
\hline & Lw (CDS) & $-12,2 \%$ & $-13,2 \%$ & $-12,7 \%$ & $-15,7 \%$ & $-16,4 \%$ & $-15,1 \%$ & $-7,3 \%$ & $-7,4 \%$ & $-6,9 \%$ \\
\hline & Rf (SDS) & $-13,6 \%$ & $-13,3 \%$ & $-13,0 \%$ & $-14,1 \%$ & $-13,8 \%$ & $-13,1 \%$ & $-7,3 \%$ & $-7,2 \%$ & $-6,4 \%$ \\
\hline & Rf (CDS) & $-12,7 \%$ & $-13,6 \%$ & $-13,6 \%$ & $-15,6 \%$ & $-16,3 \%$ & $-15,8 \%$ & $-7,6 \%$ & $-7,3 \%$ & $-7,4 \%$ \\
\hline & Dp (SDS) & $-11,0 \%$ & $-10,8 \%$ & $-11,7 \%$ & $-12,5 \%$ & $-11,8 \%$ & $-10,6 \%$ & $-7,5 \%$ & $-6,4 \%$ & $-5,3 \%$ \\
\hline & Dp (CDS) & $-8,3 \%$ & $-7,8 \%$ & $-14,9 \%$ & $-13,4 \%$ & $-14,1 \%$ & $-13,1 \%$ & $-9,0 \%$ & $-6,6 \%$ & $-6,3 \%$ \\
\hline
\end{tabular}

Nota: *em negrito encontram-se os maiores valores.

Nota-se na Tabela 8 que alterar o setpoint em $1{ }^{\circ} \mathrm{C}$ reduziu em até $16 \%$ o consumo de energia do ar condicionado. Essa alteração causou maiores economias em Curitiba (8\%-15\%) e São Paulo (12\%-16\%) do que em Manaus (5\%-9\%). Friess, Rakhshan e Davis (2017) afirmam que a utilização de um setpoint de resfriamento mais alto $\left(27^{\circ} \mathrm{C}\right)$ em locais de climas quentes só é possível quando se tem uma edificação com menos isolamento, o que permite maiores trocas de calor com o ambiente exterior.

\section{Conclusões}

Com o objetivo de classificar e caracterizar o desempenho energético de edifícios de planta livre em climas brasileiros, a influência dos parâmetros relacionados à fachada foi analisada, a partir de simulações computacionais no programa EnergyPlus.
Para esse tipo de edificação, foi verificada a influência dos seguintes parâmetros:

(a) tipo de fachada;

(b) clima;

(c) parâmetros relacionados às aberturas (PAF, tipo de vidro e dispositivo de sombreamento); e

(d) temperatura de setpoint de resfriamento do ar condicionado, cujos resultados são apresentados na Tabela 5.

A partir da análise paramétrica realizada nessa pesquisa e da classificação dos resultados apresentados no Quadro 5, foi possível avaliar a influência de cada parâmetro no consumo de energia do ar condicionado. Com isso, pode-se gerar recomendações de projeto específicas para edifícios de escritórios de planta livre localizados em climas brasileiros. Assim, as características arquitetônicas presentes nas melhores classificações (verdes), são apresentadas no Quadro 6. 
Quadro 5 - Principais resultados obtidos nessa pesquisa

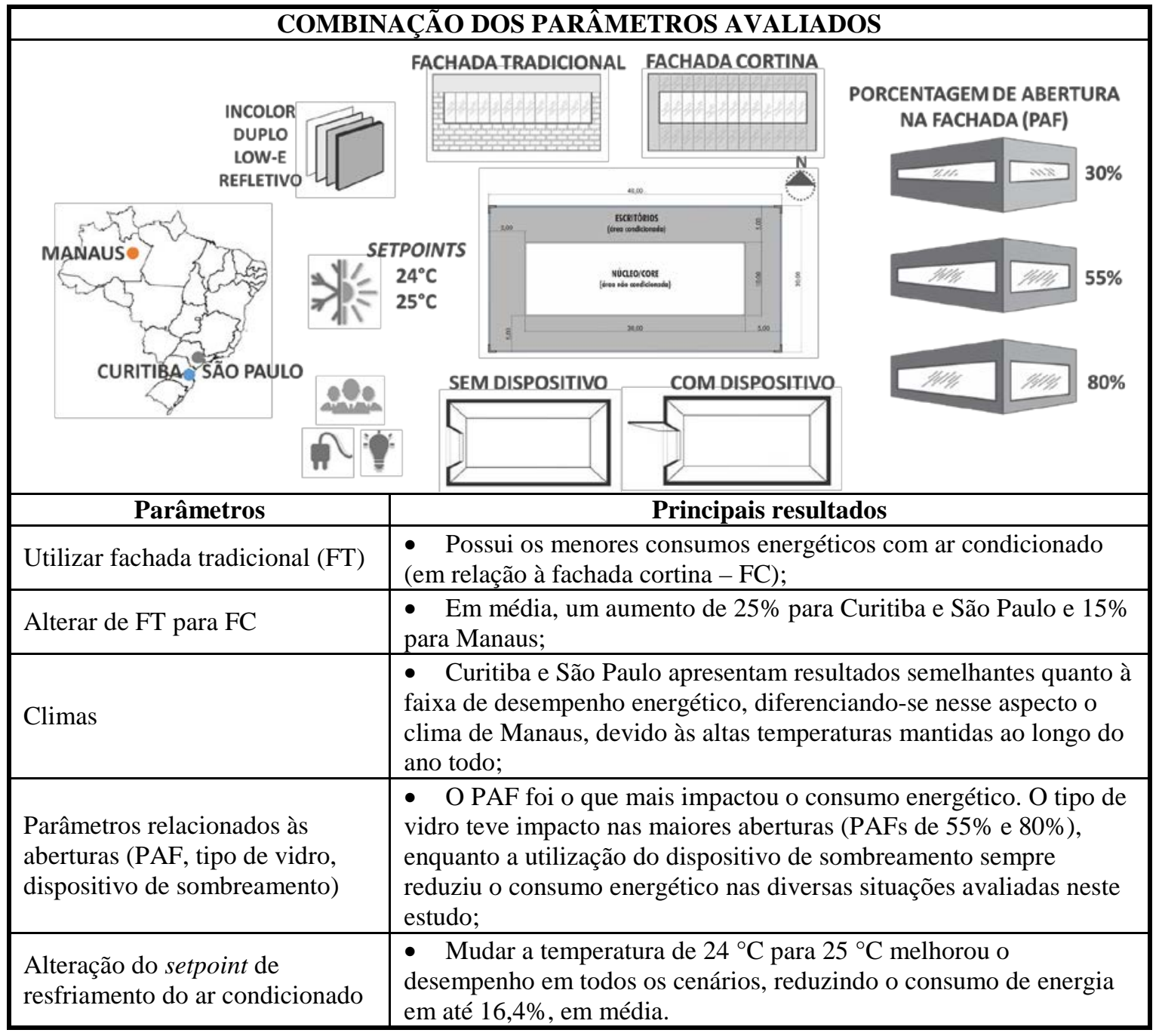

\section{Quadro 6 - Principais recomendações de projeto para os melhores desempenhos}

\begin{tabular}{|l|l|}
\hline \multicolumn{1}{|c|}{ Características } & \multicolumn{1}{c|}{ Recomendações } \\
\hline $\begin{array}{l}\text { Fachada tradicional } \\
\text { (FT) }\end{array}$ & $\begin{array}{l}\bullet \quad \text { Utilizar, em todos os climas, a fachada tradicional, exceto para os } \\
\text { cenários com aberturas grandes (PAF de 80\%) e setpoint de } 24^{\circ} \mathrm{C} \text { em } \\
\text { Manaus. }\end{array}$ \\
\hline \multirow{2}{*}{$\begin{array}{l}\text { Fachada cortina } \\
\text { (FC) }\end{array}$} & $\begin{array}{l}\text { Em Curitiba e São Paulo deve-se priorizar janelas pequenas (PAF de } \\
\text { utilizar todos os tipos de vidros (nos dois setpoints). É possível se utilizar } \\
\text { janelas grandes (PAF de 80\%) em Curitiba, desde que se mantenha o } \\
\text { setpoint em } 25^{\circ} \mathrm{C} \text { para todos os tipos de vidros (exceto o incolor) e, em São } \\
\text { Paulo, é possível utilizar o vidro refletivo no setpoint de } 24^{\circ} \mathrm{C} \text { e os vidros } \\
\text { low-e, refletivo ou duplo no setpoint de } 25^{\circ} \mathrm{C} \text {. Em climas muito quentes, } \\
\text { como Manaus, o uso de janelas pequenas (PAF de } 30 \% \text { ) é mais adequado e, } \\
\text { com a possibilidade de se utilizar um dispositivo de sombreamento, pode-se } \\
\text { utilizar os vidros refletivo ou duplo e, no setpoint de } 25^{\circ} \mathrm{C} \text {, todos os tipos de } \\
\text { vidro podem ser usados (exceto o incolor). É possível se utilizar janelas } \\
\text { médias (PAF de 55\%), desde que se tenha dispositivo de sombreamento } \\
\text { para os vidros refletivo ou duplo, no setpoint de } 25^{\circ} \mathrm{C} .\end{array}$ \\
\hline
\end{tabular}


Têm-se as seguintes limitações desse estudo:

(a) não foi considerado o aproveitamento da iluminação natural, através da utilização de sistemas eficientes (dimerizáveis), que poderiam reduzir o consumo energético total do edifício. Entretanto, a consideração desse aspecto acarretaria outras análises no que tange à disponibilidade e qualidade da luz natural, otimizando questões de aproveitamento da iluminação proveniente das aberturas, evitando, por exemplo, o ofuscamento e/ou o superaquecimento próximo às aberturas;

(b) foi utilizado um tamanho de dispositivo de sombreamento que proporcionasse a maior máscara de sombra e, assim, fosse suficiente para prover o sombreamento efetivo para as demais situações, ainda que esse sombreamento fosse maior que o necessário;

(c) foi mantida a mesma orientação solar para todos os cenários avaliados, com as maiores fachadas voltadas à norte-sul, em função de se optar pela situação que gerasse menores ganhos solares para o volume como um todo;

(d) além disso, foi avaliada a mesma geometria (retangular), com uma grande área central destinada ao core, como foi identificado na coleta de dados a respeito desse tipo de edificação utilizada no Brasil; e

(e) as densidades de pessoas e equipamentos foram dados fixos da simulação, pois estão diretamente relacionadas ao uso de tais espaços, não podendo, portanto, serem previstos com exatidão no desenvolvimento do projeto arquitetônico.

Como indicações de trabalhos futuros têm-se:

(a) trabalhar com outras geometrias, a fim de identificar como as alterações dos parâmetros da fachada influenciam no desempenho energético dessas edificações;

(b) avaliar outros tipos de fachadas, como as duplas ventiladas, revestidas com vegetação e outros materiais (como a utilização de painéis fotovoltaicos e os materiais de mudança de fase PCMs, por exemplo);

(c) incluir nas análises o aproveitamento da iluminação natural (através da integração com a iluminação artificial, por meio de um sistema dimerizável), a fim de se compreender o quanto essa parcela influencia no consumo de energia total desse tipo de edificação. Além disso, pode-se avaliar a qualidade da iluminação interior, detectando casos com ofuscamento, por exemplo, para gerar espaços com melhor conforto visual aos usuários; (d) utilizar estratégias passivas, como a ventilação natural - que pode ser realizada por meio de sistemas híbridos de ventilação (combinação de ventilação natural e uso de sistemas de condicionamento térmico artificial), pode auxiliar tanto na redução do consumo energético quanto na melhoria do conforto térmico no interior desse tipo de edificação; e

(e) considerar o conforto térmico nas análises, a fim de verificar a relação conforto versus desempenho energético.

Com isso, esta etapa da pesquisa estudou uma gama de combinações de diversos parâmetros relacionados à fachada e demonstrou a sua influência. Tais resultados podem servir de suporte à tomada de decisões por parte dos projetistas, no sentido de se criar edifícios energeticamente mais eficientes. É importante destacar que tais resultados estão diretamente relacionados ao modelo e climas selecionados para este estudo, não podendo, portanto, ser considerados para situações diferentes das avaliadas neste estudo.

\section{Referências}

ALVARES, C. A. et al. Köppen's Climate Classification Map for Brazil. Meteorologische Zeitschrift, v. 22, n. 6, p. 711-728, 2013.

AMERICAN SOCIETY OF HEATING, REFRIGERATING AND AIRCONDITIONING ENGINEERS. Handbook of Fundamentals. Atlanta, 2009.

\section{AMERICAN SOCIETY OF HEATING, REFRIGERATING AND AIRCONDITIONING ENGINEERS. Standard 90.1-2013: energy standard for buildings except low-rise residential buildings. Atlanta, 2013.}

ASSOCIAÇÃO BRASILEIRA DE NORMAS TÉCNICAS. NBR 15220-2: desempenho térmico de edificações: parte 2: métodos de cálculo da transmitância térmica, da capacidade térmica, do atraso térmico e do fator solar de elementos e componentes de edificações. Rio de Janeiro, $2005 a$.

ASSOCIAÇÃO BRASILEIRA DE NORMAS TÉCNICAS. NBR 15220-3: desempenho térmico de edificações: parte 3: zoneamento bioclimático brasileiro e diretrizes construtivas para habitações unifamiliares de interesse social. Rio de Janeiro, $2005 b$.

ASSOCIAÇÃO BRASILEIRA DE NORMAS TÉCNICAS. NBR 16401-1: instalações de arcondicionado, sistemas centrais e unitários: parte 1: projetos das instalações. Rio de Janeiro, 2008. 
AYOADE, J. O. Introdução à Climatologia Para os Trópicos. 4. ed. Rio de Janeiro: Bertrand Brasil, 1996.

AZARI, R. Integrated Energy and Environmental Life Cycle Assessment of Office Building Envelopes. Energy and Buildings, v. 82, p. 156162, 2014.

BESEN, P.; WESTPHAL, F. S. Fachadas de Vidro no Brasil: um estudo comparativo de viabilidade econômica. In: ENCONTRO NACIONAL DE TECNOLOGIA DO AMBIENTE CONSTRUÍDO, 16., Maceió, 2014. Anais... Maceió, 2014.

BESEN, P.; WESTPHAL, F. S. Uso de Vidro Duplo e Vidro Laminado no Brasil: avaliação do desempenho energético e conforto térmico por meio de simulação computacional. In: ENCONTRO NACIONAL DE TECNOLOGIA DO AMBIENTE CONSTRUÍDO, 14.., Juiz de Fora, 2012. Anais... Juiz de Fora, 2012.

BORGSTEIN, E. H.; LAMBERTS, R.; HENSEN, J. L. M. Evaluating Energy Performance in NonDomestic Buildings: a review. Energy and Buildings, v. 128, p. 734-755, 2016.

BOYANO, A.; HERNANDEZ, P.; WOLF, O. Energy Demands and Potential Savings in European Office Buildings: case studies based on EnergyPlus simulations. Energy and Buildings, v. 65, p. 19-28, 2013.

BUILDINGS. Pesquisa Imobiliária Inteligente: primeira empresa brasileira especializada em pesquisa imobiliária corporativa. Disponível em: $<$ http://www.buildings.com.br>. Acesso em: 2 fev. 2016.

CARLO, J. C. Desenvolvimento de Metodologia de Avaliação da Eficiência Energética do Envoltório de Edificações Não-residenciais. Florianópolis, 2008. Tese (Doutorado em Engenharia Civil) - Escola de Engenharia, Universidade de Santa Catarina, Florianópolis, 2008.

CARVALHO, M. M. Q.; LA ROVERE, E. L.; GONÇALVES, A. C. M. Analysis of Variables That Influence Electric Energy Consumption in Commercial Buildings in Brazil. Renewable and Sustainable Energy Reviews, v. 14, n. 9, p. 3199-3205, 2010.

CB3E; ABIVIDRO. Catálogo de Propriedades Térmicas e Óticas de Vidros Comercializados no Brasil. Universidade Federal de Santa Catarina. Centro tecnológico. Departamento de Engenharia Civil, Florianópolis, 2015. Disponível em: <http://www.pbeedifica.com.br/etiquetagem/reside ncial/planilhas-catalogos>.
CEBRACE. Características do Vidro Laminado Incolor. Relatório interno, 2016.

CONSELHO BRASILEIRO DE CONSTRUÇÃO SUSTENTÁVEL. Aspectos da Construção Sustentável no Brasil e Promoção de Políticas Públicas: subsídios para a promoção da construção civil sustentável. Ministério do Meio Ambiente. Programa das Nações Unidas para o Meio Ambiente (PNUMA), 2014. Disponível em: $<$ http://www.cbcs.org.br/_5dotSystem/userFiles/M MA-

Pnuma/Aspectos\%20da\%20Construcao\%20Susten tavel\%20no\%20Brasil\%20e\%20Promocao\%20de \%20Politicas\%20Publicas.pdf>. Acesso em: 12 nov. 2014.

DALZIEL, R. Architecture. In: The Commercial Offices Handbook. London: RIBA Enterprises, 2003.

\section{DEPARTMENT OF ENERGY EFFICIENCY} AND RENEWABLE ENERGY. EnergyPlus: version 8.1. Office of Building Technologies, 2013.

DIDONÉ, E. L.; WAGNER, A.; PEREIRA, F. O. R. Estratégias Para Edifícios de Escritórios Energia Zero no Brasil Com Ênfase em BIPV.

Ambiente Construído, Porto Alegre, v. 14, n. 3, p. 27-42, jul./set. 2014.

EMPRESA DE PESQUISA ENERGÉTICA.

Balanço Energético Nacional 2018: ano base 2017. Relatório Final. Rio de Janeiro, 2018.

FRIESS, W. A.; RAKHSHAN, K.; DAVIS, M. P. A Global Survey of Adverse Energetic Effects of Increased Wall Insulation in Office Buildings: degree day and climate zone indicators. Energy Efficiency, v. 10, n. 1, p. 97-116, 2017.

GLASSEC-VIRACON. Características do Vidro Opaco. Relatório interno, 2016.

GUARDIAN. Manual Técnico Guardian SunGuard: vidros de controle solar e eficiência energética. 2010. Disponível em:

$<$ http://www.sunguardglass.com>. Acesso em: 13 abr. 2016.

HUANG, Y.; NIU, J. Optimal Building Envelope Design Based on Simulated Performance: history, current status and new potentials. Energy and Buildings, v. 117, p. 387-398, 2015.

IHARA, T.; GUSTAVSEN, A.; JELLE, B. P. Effect of Facade Components on Energy Efficiency in Office Buildings. Applied Energy, v. 158, p. 422-432, 2015. 
INSTITUTO NACIONAL DE METROLOGIA, NORMALIZAÇÃO E QUALIDADE

INDUSTRIAL. RTQ-C: regulamento técnico da qualidade para o nível de eficiência energética de edificações comerciais, de serviços e públicas. Rio de Janeiro, 2013.

KÖPPEN, W. Das Geographische System der Klimate. In: KÖPPEN, W.; GEIGER, R. (Eds.). Handbuch der Klimatologie. Berlin: Gebruder Borntrager, 1936.

KRSTIĆ-FURUNDŽIĆ, A.; KOSIĆ, T. Assessment of Energy and Environmental Performance of Office Building Models: a case study. Energy and Buildings, v. 115, p. 11-22, 2016.

\section{LABORATÓRIO DE EFICIÊNCIA} ENERGÉTICA EM EDIFICAÇÕES. Arquivos Climáticos INMET 2015. 2016. Disponível em: $<$ http://www.labeee.ufsc.br/downloads/arquivosclimaticos/inmet2015>. Acesso em: 30 mai. 2016.

MARCONDES, M.; ALUCCI, M.;

GONÇALVES, J. Façades and Office Buildings in São Paulo (Brazil): aiming for thermal comfort and natural ventilation. In: WINDSOR

CONFERENCE: The Changing Context of Comfort in an Unpredictable World, n. 7, p. 1215, apr. 2012.

MELO, A. P. et al. Is thermal Insulation Always Beneficial in Hot Climate? In: CONFERENCE OF INTERNATIONAL BUILDING PERFORMANCE SIMULATION ASSOCIATION, 14., Hyderabad, 2015. Proceedings... Hyderabad, 2015.

MELO, A. P.; LAMBERTS, R. Opaque Envelope Parameters Versus Energy Consumption in Commercial Buildings in Brazil. Journal of Building Performance Simulation, v. 1, n. 4, p. 237-244, 2008.

MIRRAHIMI, S. et al. The Effect of Building Envelope on the Thermal Comfort and Energy Saving For High-Rise Buildings in Hot-Humid Climate. Renewable and Sustainable Energy Reviews, v. 53, p. 1508-1519, 2016.

NEVES, L. de O.; MARQUES, T. H. T. Building Envelope Energy Performance of High-Rise Office Buildings in Sao Paulo City, Brazil. Procedia Environmental Sciences, v. 38, p. 821-829, 2017.

PASQUALI, F. E. et al. Potential for Energy Savings in Retrofiting of an Office Building in São Paulo. In: CONFERENCE OF INTERNATIONAL BUILDING PERFORMANCE SIMULATION ASSOCIATION, 12., Sydney, 2011. Proceedings... Sydney, 2011.
PÉREZ-LOMBARD, L.; ORTIZ, J.;

VELÁZQUEZ, D. Revisiting Energy Efficiency Fundamentals. Energy Efficiency, v. 6, n. 2, p. 239-254, 2013.

RAJI, B.; TENPIERIK, M. J.; VAN DEN DOBBELSTEEN, A. An Assessment of EnergySaving Solutions For the Envelope Design of High-Rise Buildings in Temperate Climates: a case study in the Netherlands. Energy and Buildings, v. 124, p. 210-221, 2015.

ROLIM, G. de S. et al. Classificação Climática de Köppen e de Thornthwaite e Sua Aplicabilidade na Determinação de Zonas. Bragantia, v. 66, n. 4, p. 711-720, 2007.

RORIZ, M. Arquivos Climáticos de Municípios Brasileiros. Associação Nacional de Tecnologia do Ambiente Construído. Grupo de Trabalho sobre Conforto e Eficiência Energética de Edificações. Relatório interno. Disponível em:

$<$ http://www.labeee.ufsc.br/downloads/arquivosclimaticos>. Acesso em: 9 out. 2012.

RUZICKI, S. et al. Análise da Sensibilidade do RTQ-C Quanto a Variação da Densidade de Carga Interna de Edificações de Escritórios nas Zonas Bioclimáticas Brasileiras 1, 2 e 3. In: ENCONTRO NACIONAL DE TECNOLOGIA DO AMBIENTE CONSTRUÍDO, 16., São Paulo, 2016. Anais... São Paulo, 2016.

SANTANA, M. V. Influência de Parâmetros Construtivos no Consumo de Energia de Edifícios de Escritório Localizados em Florianópolis-SC. Florianópoli, 2006. Dissertação (Mestrado em Engenharia Civil) Escola de Engenharia, Universidade Federal de Santa Catarina, Florianópolis, 2006.

TSIKALOUDAKI, K. et al. Assessing Cooling Energy Performance of Windows for Residential Buildings in the Mediterranean Zone. Energy Conversion and Management, v. 64, p. 335-343, 2012.

VENÂNCIO, R.; PEDRINI, A. The Influence of Design Decisions on Energy Consumption and Thermal Performance: the case of UFRN Campus, Brazil. In: INTERNATIONAL IBPSA CONFERENCE, 11., Glasgow, 2009. Proceedings... Glasgow, 2009.

VERONEZI, A. B. P.; LIMA JUNIOR, J. da R.; ALENCAR, C. T. de. Sistema de Classificação de Edifícios de Escritórios no Brasil. In: SEMINÁRIO INTERNACIONAL DA LARES, 5., São Paulo, 2005. Anais... São Paulo, 2005. 
WESTPHAL, F. S. Análise de Incertezas e de Sensibilidade Aplicadas à Simulação de Desempenho Energético de Edificações Comerciais. Florianópolis, 2007. Tese (Doutorado em Engenharia Civil) - Escola de Engenharia, Universidade Federal de Santa Catarina, Florianópolis, 2007.

WESTPHAL, F. S.; ANDREIS, C. Influence of Glazed Façades on Energy Consumption For Air Conditioning of Office Buildings in Brazilian Climates. Journal of Engineering Research and Application, v. 6, n. 11, p. 54-60, 2016.
WESTPHAL, F. S.; LAMBERTS, R. Análise do Impacto de Variáveis Arquitetônicas e Cargas Internas no Consumo de Energia em Condicionamento de Ar de Edificações Comerciais. In: ENCONTRO NACIONAL, 9.; LATINO AMERICANO DE CONFORTO NO AMBIENTE CONSTRUÍDO, 5., Ouro Preto, 2007. Anais...Ouro Preto, 2007.

YOSHINO, H.; HONG, T.; NORD, N. IEA EBC Annex 53: total energy use in buildings, analysis and evaluation methods. Energy and Buildings, v. 152, p. 124-136, mar. 2017.

\section{Agradecimentos}

Os autores agradecem à Coordenação de Aperfeiçoamento de Pessoal de Nível Superior (Capes) pelo apoio e fomento a este trabalho de pesquisa.

\section{Rosilene Regolão Brugnera}

Instituto de Arquitetura e Urbanismo | Universidade de São Paulo | Av. Trabalhador Sancarlense, 400, Parque Arnold Schimidt | São Carlos - SP - Brasil | CEP 13566-590 | E-mail: rosileneregolao@gmail.com

\section{Ricardo Mateus}

Departamento de Engenharia Civil, Centro de Investigação em Território, Ambiente e Construção | Universidade do Minho | Alameda da Universidade, Azurém | Guimarães - Portugal | CEP 4800058 | Tel.: +(351) 25351-0200 | E-mail: ricardomateus@civil.uminho.pt

\section{J oão Adriano Rossignolo}

Faculdade de Zootecnia e Engenharia de Alimentos | Universidade de São Paulo | Av. Duque de Caxias Norte, 225, Campus da USP, Centro | Pirassununga - SP - Brasil | CEP 13635-900 | Tel.: (19) 3565-4284 | E-mail: jarossig@sc.usp.br

\section{Karin Maria Soares Chvatal}

Instituto de Arquitetura e Urbanismo | Universidade de São Paulo | Tel.: (16) 3373-8600 | E-mail: karin@sc.usp.br

\section{Revista Ambiente Construído}

Associação Nacional de Tecnologia do Ambiente Construído

Av. Osvaldo Aranha, 99 - 3o andar, Centro

Porto Alegre - RS - Brasil

CEP $90035-190$

Telefone: +55 (51) 3308-4084

Fax: +55 (51) 3308-4054

www. seer. ufrgs. br/ ambienteconstruido

E-mail: ambienteconstruido@ufrgs.br

This is an open-access article distributed under the terms of the Creative Commons Attribution License. 